\title{
FANPCE TECHNIQUE FOR RISK ASSESSMENT ON SUBWAY STATION CONSTRUCTION
}

\author{
Luyuan WU®1) Haibo BAI ${ }^{1 *}$, Chao YUAN ${ }^{2}$, Changyu XU1 \\ ${ }^{1}$ State Key Laboratory for Geo mechanics and Deep Underground Engineering, \\ China University of Mining and Technology, Xuzhou 221116, Jiangsu, China \\ ${ }^{2}$ Department of Architecture and Civil Engineering, Xian University of Science and Technology, \\ Xian 710054, Shaanxi, China
}

Received 03 November 2018; accepted 18 March 2019

\begin{abstract}
Risk assessment is critical for the construction of the subway station to improve the risk management and reduce the additional loss. According to field investigation of safe construction, the analytical network process (ANP), fuzzy set theory and fuzzy comprehensive evaluation (FCE), a fuzzy ANP comprehensive evaluation (FANPCE) model was proposed to evaluate the risk of subway station construction in this paper. Twelve key risk factors of subway station construction were identified through literature review and questionnaires. The interdependency among risk factors were illustrated through the network structure of ANP, and then a weight matrix of single risk factors was built by comments and survey results, and the interdependent weight matrix was quantified by integrating the triangular fuzzy number into the ANP. Subsequently, the total risk rank of assessed projects can be quantified though the synthesis of weight matrices with the synthetic operator of FCE. Wu Lu Kou subway station was selected as a case study. The results imply that, construction experience, underground water, and safety consciousness have a substantial influence on construction projects and that the total construction risk of $\mathrm{Wu} \mathrm{Lu} \mathrm{Kou} \mathrm{subway} \mathrm{station} \mathrm{is} \mathrm{ranked} \mathrm{at} \mathrm{I} \mathrm{level.} \mathrm{Moreover,} \mathrm{the} \mathrm{loss} \mathrm{analysis} \mathrm{of} \mathrm{the} \mathrm{whole} \mathrm{construc-}$ tion process verifies this method. This research contributes to developing a FANPCE method to identify the risk factors with high weights, assess the risk rank of projects and appropriately respond to the results. In addition, the developed fuzzy set theory-ANP-FCE integrated network provides stakeholders a consolidated model for the risk evaluation.
\end{abstract}

Keywords: construction risk, subway station, risk identification, ANP, risk assessment, FANPCE method.

\section{Introduction}

Subterranean engineering, especially the subway engineering, is an effective method to alleviate the traffic congestion. Statistically, approximately 2476 subway stations and 4136 subway $\mathrm{km}$ have been constructed or are planned from 2014 to 2021 in 23 cities of China (Hu \& Qin, 2013; H. R. Li, Q. M. Li, \& Lu, 2017). However, the complicated construction environment, immature construction techniques and inadequate construction experience can probably result in project delay, additional cost and engineering accidents (Qian, 2012; Xiong, Lu, Wang, Qian, \& Rong, 2018). Figure 1 shows the data of subway accidents in China from 2003 to 2017 according to the official data and literature (Li, Du, \& Zhang, 2014; Li et al., 2017). Since 2011, the number of subway accidents and casualties has increased as shown in Figure 1.
Therefore, it is critical to improve the risk management techniques in the construction of subway stations, so as to reduce the risk and ensure the construction safety. The risk assessment of subway construction has been investigated by many scholars, and many methods have been employed to assess the probability of construction risk. Mahamid (2011) ranked risk events by Risk Matrix (RM) based on qualitative analyses of risk components. However, the risk classification is limited to a number of categories in this method. According to FTA, Zhang, Wang, and Hu (2011) assessed the safety of row piles in excavation engineering; while FTA must identify the accurate failure rate of each event (Li et al., 2018), and FTAs established by different people have different results. Roy (2010), Nývlt, Prívara, and Ferkl (2011) presented scenario analysis methods that

*Corresponding author. E-mail: wymwly2017@126.com 


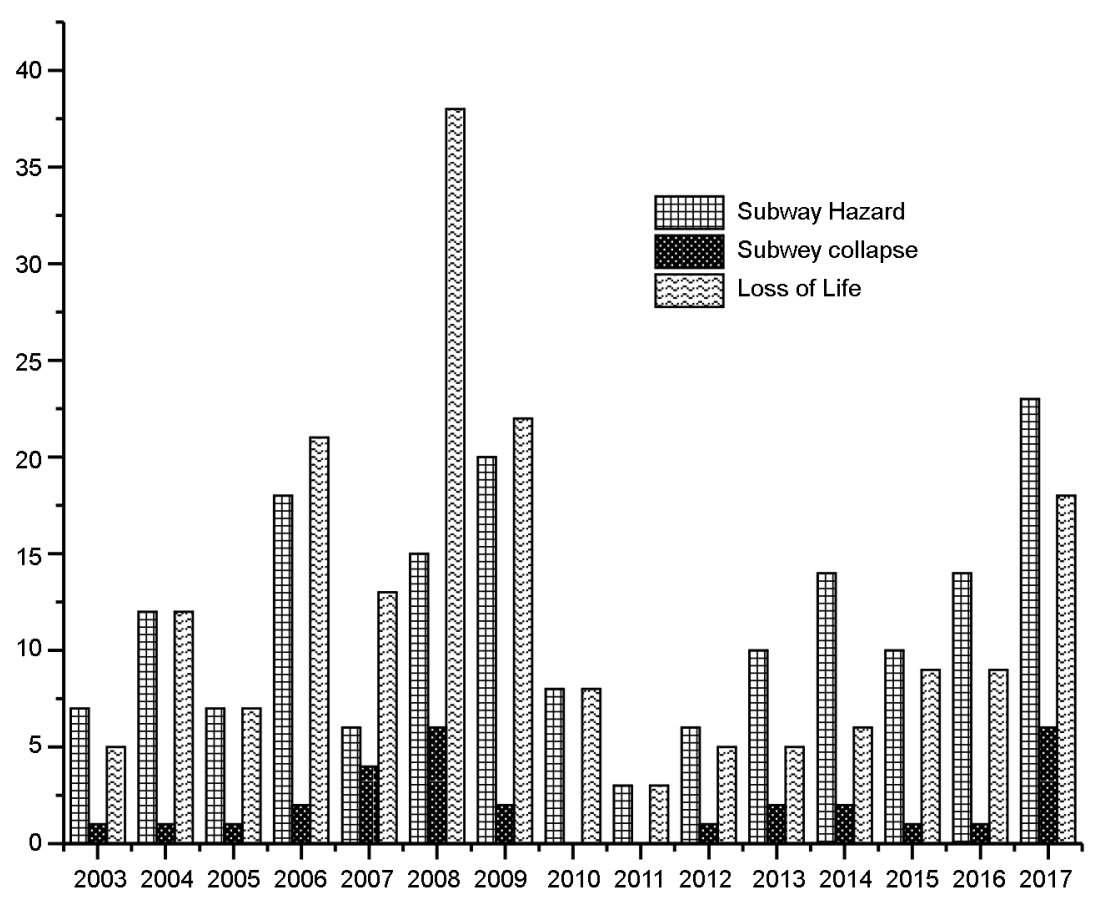

Figure 1. Statistics of subway accident in China from 2003-2017

can test possible consequences for alternative scenarios in a project, but a lot of data were required to evaluate the probability of an event. The work breakdown structure (WBS)-based method (Klein, Powell, \& Chapman, 1994; Seyedhoseini, Noori, \& Hatefi, 2009) analyzes construction risk by dividing the total risk into many smaller risks (Ma, Rezania, Yu, \& Bai, 2017; Ma, Cai, Zhou, \& $\mathrm{Li}, 2018 \mathrm{a}$ ). Moreover, it is difficult to determine the WBS for some complicate projects and quantize the risk by the single WBS-based method. Kuo and Lu (2013) employed a FMCDM approach (the integration of consistent fuzzy preference relations and fuzzy multiple attributes direct rating) to systematically assess risk for the metropolitan construction.

Considering the limitations of existing methods, further research on the risk assessment should be performed from other perspectives. AHP, fuzzy AHP, and AHP-ANP are prevailing methods for decision-making analysis (Jie, Hu, Q. Y. Li, \& G. X. Li, 2004; Zhao, Chen, Pan, \& Lu, 2017). The elements of a system can be aggregated into hierarchical or element groups that have similar properties without interactions or dominance relationships among elements within a hierarchy (Saaty, 2001; Guo, Shang, \& Li, 2011). Sharma, Roy, Kar, and Prentkovskis (2018) evaluated the performance of Indian railway stations (IRS) through integrating rough numbers, AHP and multi-attribute border approximation area comparison (MABAC) methods in rough environment. Roy, Chatterjee, Bandyopadhyay, and Kar (2018) proposed a systematic evaluation and assessment approach by incorporating ANP and multi-attributive border approximation area comparison methods in the rough environment. In the practical application, however, the elements of a system are generally connect- ed rather than organized in a hierarchical structure, then a network structure with a preferable form is produced. The ANP technique enables more complex relationships among decision levels, attribute, analyses of the uncertainty and ambiguity of a system and project (Saaty, 2001; Chu et al., 2017; Tavana, Zandi, \& Katehakis, 2013; Chatterjee, Bandyopadhyay, Ghosh, \& Kar, 2015; Bu-Qammaz, Dikmen, \& Birgonul, 2009). Since risk factors are indeterminate, abstract, and uncertain, it is difficult to quantify risk factors. Considering the impact of all risk factors comprehensively, Fuzzy comprehensive evaluation (FCE) can assess the total risk, distinguish the importance of various factors by the weight setting and the possible risk determination with various degrees. The maximum influence is the final determination value of the risk level (Chu et al., 2017). Li et al. (2014) and Ying, Wang, Zhu, Lei, and Qin (2016) ranked subway construction risks by a FCE model. However, compared with ANP, the interdependent and mutually restrictive relationships among risks are not fully considered. In summary, the following conditions have not been fully considered in the previous research:

- The total risk of the project is the superposition and compounding of each sub-risk, as any risk generation will have a varying impact on the overall objectives of the project. Therefore, it is necessary to identify risk factors for different projects by certain methods.

- There is an interdependent and mutually restrictive relationship between risks that need to be fully considered.

- Risk and risk analysis of subway station projects is usually dynamic throughout the entire process of project construction. 
Accident analyses and field investigations of safe construction can effectively identify the risk factors for subway station projects. ANP technique handles interactions among elements by obtaining the composite weights via the development of a super matrix (Dağdeviren, Yüksel, \& Kurt, 2008; Chatterjee, Zavadskas, Tamošaitienè, Adhikary, \& Kar, 2018). Triangular fuzzy numbers (TFNs) derived from the concept of Dev fuzzy sets can effectively quantify the uncertainty and ambiguity. The fuzzy comprehensive evaluation (FCE) can transform the fuzzy relations between evaluated risk factors and evaluated projects into a fuzzy relationship between the evaluated project and the evaluation grade. lows:

Thus, the main objectives of this research are as fol-

- Identifying and classifying risk factors of subway construction projects based on statistics and site risk investigation with effective questionnaires.

- Developing a logical model integrating fuzzy set theory, ANP, and FCE for risk assessment for the subway station construction.

- Assessing the risk level of subway station construction based on the FANPCE method in diffident construction processes.

This paper is organized as follows. The FANPCE method is introduced in Section 2. Details of the development of the FANPCE model are provided in Section 3. The application of the model and the construction risk evaluation of Wu Lu Kou subway station are presented in Section 4. Section 5 discusses these findings, and Section 6 presents the conclusions.

\section{Literature review}

MCDM methods and improved method have been extensively applied in the realm of project risk management, and optimized to process various types of uncertainties encountered in the decision-making process. Antuchevičienè, Zavadskas, and Zakarevičius (2010) supplemented TOPSIS (Technique for the Order Preference by Similarity to Ideal Solution) method and integrated the Mahalanobis distance in the usual algorithm of TOPSIS for investigating multiple criteria construction management decisions issue. Vafadarnikjoo, Mobin, and Firouzabadi (2016) presented an intuitive fuzzy decisionmaking trial and evaluation laboratory (DEMATEL) to prioritize risks associated with construction projects by the risk breakdown structure. Debnath, Roy, Kar, Zavadskas, and Antucheviciene (2017) combined modified grey DEMATEL, Multi-Attributive Border Approximation area Comparison and sensitivity analysis to evaluate and select the genetically modified agro portfolio. Zavadskas, Turskis, and Tamošaitiene (2010) presented risk assessment of construction projects by applying TOPSIS gray and COPRAS-G methods based on multi attribute decision-making methods. Taylan, Bafail, Abdulaal, and Kabli (2014) developed hybrid methodologies based on fuzzy AHP and fuzzy TOPSIS and applied the relative importance index method to prioritize the project risks based on the obtained data. Yang, Said, Lin, and Zheng (2018) presented a novel methodology to determine the overall highway safety level through statistical analysis and ANP with set pair analysis (SPA). D. Shin, Y. Shin, and Kim (2016) performed a comparative analysis of AHP and fuzzy AHP to evaluate the potential risk factors at the construction site of a nuclear power plant. Santos and Jungles (2016) evaluated the completion of construction project risk by considering the correlation of delay and the schedule performance index along with any time overrun. Ahmadi, Behzadian, Ardeshir, and Kapelan (2016) analyzed the criteria to prioritize potential risk events and quantified them by fuzzy AHP. Ulubeyli and Kazaz (2016) developed a fuzzy-based subcontractor selection model for globally based construction projects. Lin, Chen, and Chuang (2016) presented a Hybrid Multiple Criteria Decision-Making Model by combining DEMATEL with D-ANP (DEMATEL based ANP) and VIKOR methods to improve project risk management. Chatterjee et al. (2018) extended the ANP methodology in the D numbers domain to handle three types of ambiguous information. Valipour, Yahaya, Noor, Antucheviciene, and Tamošaitiene (2017) proposed a Stepwise Weight Assessment Ratio Analysis based on a Complex Proportional Assessment framework to assess Iranian construction project risk. Chatterjee and Kar (2018) evaluated and ranked the potential alternatives by Grey-Based Complex Proportional Assessment Method.

In contrast to the abovementioned studies, this paper develops a FANPCE method by integrating ANP, triangular fuzzy numbers and FCE to assess the risk level of a subway station project.

\section{Research method}

\subsection{Analytical Network Process}

AHP technique is commonly employed for evaluating the weights of risk (Shin et al., 2016). This method employs pairwise comparisons among criteria based on expert opinions and determines the relative weights of the criteria (Saaty, 1999; Zhao et al., 2017). However, as noted by Meade and Sarkis (2002) the relationship among decision levels and attributes is ignored by AHP. Subsequently, ANP was improved by Saaty (1999) in line with AHP. Decision theories of ANP and AHP are essentially identical; the only difference between ANP and AHP is that, the former establishes a network model, whereas the latter establishes a hierarchical model (Bayazit, 2006). ANP applies and analyzes a super matrix for weight synthesis (Saaty, 2004; Zhao et al., 2017). The representation of the network model and the weight synthesis are the two main components of ANP method (Saaty, 2004; Yang et al., 2018). The structure of ANP model can be represented in the graphical form (which qualitatively represents the interactional relationships and feedback among the components) and matrix form (which qualitatively represents the degree or magnitude of the interaction or feedback). 


\subsection{Fuzzy set theory}

In most cases, the complexity of decision problems prevents the understanding of these problems with certainty (Bjegović, Krstić, \& Mikulić, 2006; Son, 2018). Fuzzy set theory, introduced by Zadeh (1965), enables the simultaneous treatment of imprecise and precise variables. Triangular fuzzy numbers, which are derived from the concept of Dev fuzzy sets (Zadeh, 1965), are applied to manage the quality and risk to solve the problems of an uncertain environment (Zimmerman, 2001). A fuzzy number is the fuzzy set $F=\left\{x \in R \mid \mu_{F}(x)\right\}$, where $x$ is in the real line. The value form $R_{1}: \infty<x<+\infty$, and $\mu_{F}(x)$ is assumed as a continuous function map. A triangular fuzzy number (TFN) can be defined by the triplet $(l, m, u)$ and the membership function (1); the membership function $\mu(x)$ can obtain values in the range [0,1] (Zimmerman, 2001; Lan \& Zhang, 2006).

$$
\mu_{F}(x)=\left\{\begin{array}{cc}
0, & x<l \cdot \text { or } \cdot x>u \\
(x-l) /(m-l), & l \leq x \leq m \\
(x-u) /(m-u), & m \leq x \leq u
\end{array},\right.
$$

where $l$ and $u$ respectively denote the lower bound and upper bound of the ambiguity degree of the judgment of $m$, and $m$ represents the mid-value $(l \leq m \leq u)$.

\subsection{Fuzzy comprehensive evaluation}

FCE method is one type of application of fuzzy mathematics (Zadeh, 1965). The basic concept of the risk evaluation of a project is described as follows: (1) consider the impact degree of all risk factors comprehensively; (2) distinguish the importance of various factors by setting weights; and (3) determine various degrees of risk possibility, in which the maximum degree is the final determination value of the risk level (Chu et al., 2017). The accuracy and reliability of the comprehensive evaluation result depend on the reasonable selection of factors and weight distributions (the weights will vary with different states and timing of the factors), synthesis of a comprehensive evaluation, and representation of results and the selection process (Dai \& Li, 2016).

\subsection{FANPCE}

Firstly, in this study, the identification of risk factors is conducted through accident analyses and questionnaires, which are designed to refine risk factors. Secondly, the occurrence of a risk event is attributed to the interaction of many factors. These factors can be coordinated with the characteristics of the structural model of ANP method, revealing the relationships among levels. Thirdly, ANP technique is adopted to establish the network structure model of risk factors. The relationships among the levels in the ANP model are assessed by the on-site engineers; Furthermore, the TFN method is used to address the vague and unquantifiable opinions of respondents. Finally, the weight of risk factors is calculated, and the fuzzy synthesis operator is used to evaluate the construction risk comprehensively. FANPCE, derived from the integration of ANP, fuzzy set theory and FCE, is a quantification method for estimating the uncertainty and ambiguity. Figure 2 shows the risk evaluation with the combination of ANP, field investigation of safe construction, fuzzy set theory and FCE. The detailed process of FANPCE is discussed in the following section.

\section{Method development}

\subsection{Establishment of comment set for subway station construction risk}

Since the final evaluation result is the evaluation vector, the construction risk of a subway station can be rated based on the maximum membership principle (Dai \& Li, 2016). Therefore, the construction risk evaluation vector $\mathbf{V}=\left\{v_{1}, v_{2}, \ldots, v_{n}\right\}$ and comment set construction risk $\mathbf{P}=\{$ I, II, III, IV $\}$ are assumed to represent the information on the membership degree of each comment level corresponding to the evaluated project. The degree of membership information corresponding to each comment level of the evaluated object is represented by this vector. If $v_{1}=\max \left\{v_{n}\right\}$, then the rating of construction risk of the subway station is I. The method separates the comments into four levels to build a comment set for subway station construction risk, i.e., $\mathbf{P}=\{$ I, II, III, IV $\}$. Table 2 shows the criteria of risk rank.

\subsection{Establishment of comment set for subway station construction risk}

The establishment of the network structure of the FANPCE method is based on the following process.

Step 1. Categorize the percentage of subway construction hazards.

Based on 178 subway construction accidents in China from 2003-2017 (Hu \& Qin, 2013; Li et al., 2014; Li et al., 2017), as shown in Figure 1, the categories and percentages of subway construction accidents are obtained in Figure 3(a). Accidents are classified as the collapse, falling, vehicle injury, lifting injury, object strike, electric shock and mechanical injury. Besides, the collapse is the most frequent accident in subway construction.

Step 2. Analyze the causes of accidents and categorize risk factors.

The causes of 178 accidents are divided into five categories: personnel risk, material risk, mechanical risk, environmental risk and system risk. The relevant percentages are shown in Figure 3(b). Then, risk factors of subway station construction are summarized based on the data of 178 subway accidents. Five first-level risk factors, ten secondlevel risk factors and 25 TLRF are identified, as shown in Figure 4.

Step 3. Design the questionnaire and field risk investigation.

If these factors are incorporated into an ANP network structure, the quantification of risk by the ANP network 


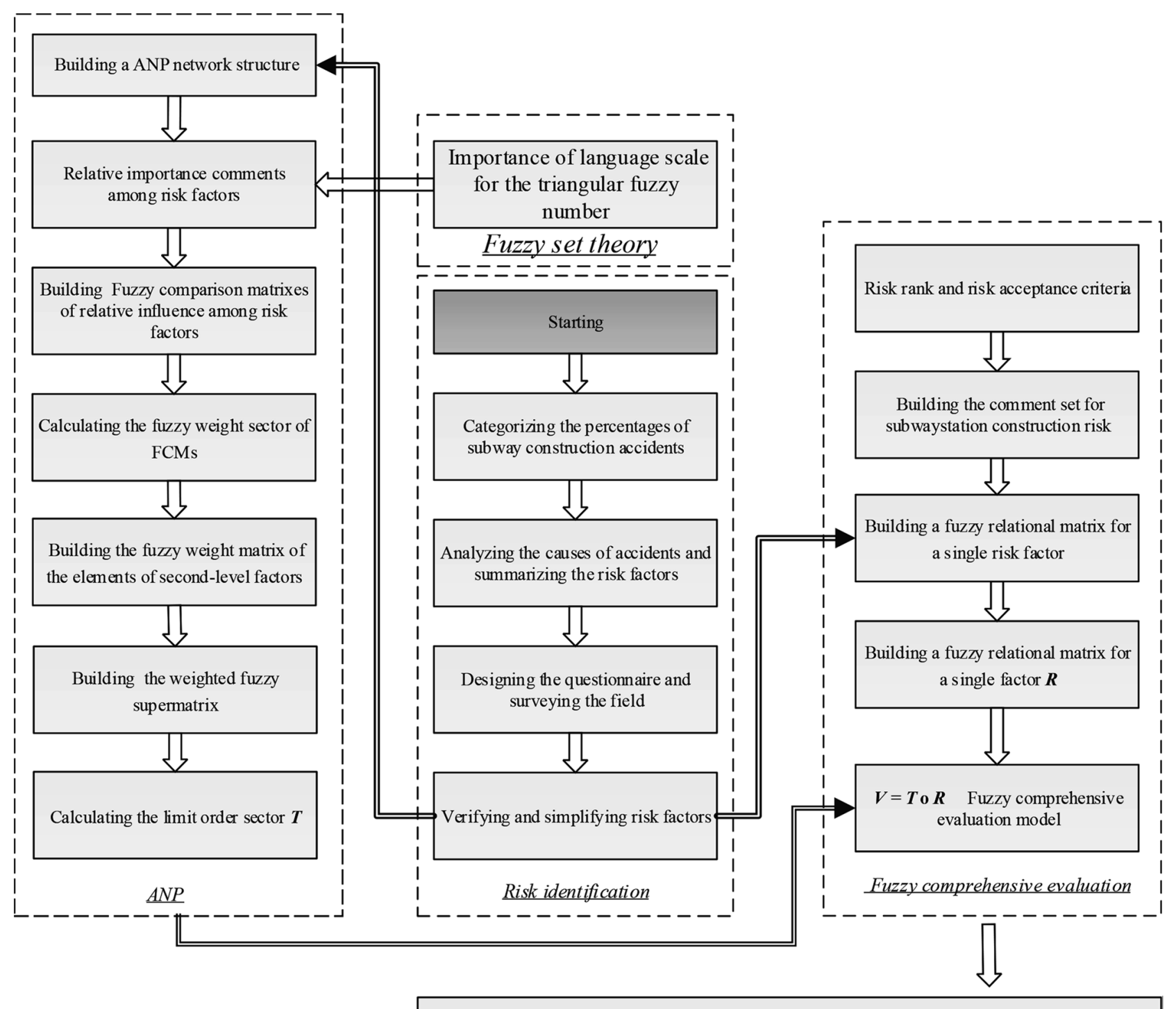

Obtaining the construction risk rank of a subway station

\section{EANPCE method}

Figure 2. Flowchart that outlines the main steps of proposed research methodology

structure is difficult, and the risk factor classification needs to be further verified. Therefore, a field risk investigation should be conducted to refine the ANP network structure, simply the calculation and verify the correctness of the statistical data.

Consequently, a questionnaire is designed for the risk identification during the subway station construction, as shown in Table 1. Design principles include that, the identification of accident types, location of occurrence, causes of accidents, loss ranks, risk probability and risk tolerability framework. Nine stations that are under construction along the subway line 4 in Xian, Shan'xi Province, China, are selected to conduct the field investigation of safe construction. Figure 5 shows the location of the field in- vestigation. 40 engineers of relevant disciplines and 10 professors of engineering management at university were investigated.

Based on the Guidelines for Tunneling Risk Management, creating risk rank and risk acceptance criteria (Eskesen, Tengborg, Kampmann, \& Veicherts, 2004; Feng, Li, \& Rostami, 2019) for subway station construction hazards (Ma, Cai, Li, \& Duan, 2018b; Ma, Duan, Liu, Li, \& Zhou, 2019) involves the simple classification of subway station accidents, as shown in Table 2. Note that weightings or combinations of different risk factors are not involved in this classification.

Subsequently, the field investigation of construction risk is carried out by analyzing potential risk events and 
Table 1. Questionnaire about risk identification for subway station construction

\begin{tabular}{|c|c|c|c|c|c|c|c|}
\hline \multicolumn{8}{|c|}{ Construction Risk Identification of Subway Station } \\
\hline \multicolumn{2}{|c|}{ Project Name } & & Engineering Section & & & & \\
\hline \multicolumn{2}{|c|}{ Completed By } & & Completion Date & & & & \\
\hline Serial number & $\begin{array}{c}\text { Risk } \\
\text { register }\end{array}$ & $\begin{array}{l}\text { Location of } \\
\text { occurrence }\end{array}$ & Risk factors & $\begin{array}{c}\text { Loss } \\
\text { ranks }\end{array}$ & $\begin{array}{c}\text { Risk } \\
\text { probability }\end{array}$ & $\begin{array}{c}\text { Risk tolerability } \\
\text { framework }\end{array}$ & Notes \\
\hline 1 (example) & $\begin{array}{l}\text { falling } \\
\text { accidents }\end{array}$ & $\begin{array}{l}\text { construction } \\
\text { scaffold }\end{array}$ & $\begin{array}{l}\text { First-layer factor }(B) ; \\
\text { Second-layer factor }\left(B_{1}\right) \text {; } \\
\text { Third-layer factor }\left(B_{11}\right)\end{array}$ & $\mathrm{C}$ & 3 & III & \\
\hline 2 & & & $\begin{array}{l}\text { First-layer factor (); } \\
\text { Second-layer factor (); } \\
\text { Third-layer factor () }\end{array}$ & & & & \\
\hline
\end{tabular}

Note: Form filling explanation: Listing the risk factors based on Figure 4, the value of loss rank, risk tolerability framework and risk probability are based on Table 2. If Figure 4 and Table 2 do not list your choice, please indicate an explanation in the notes.

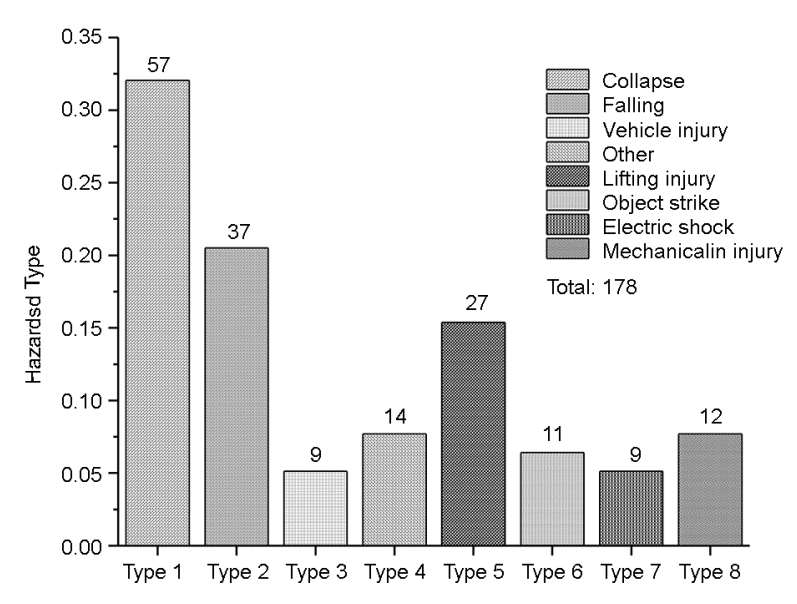

(a)

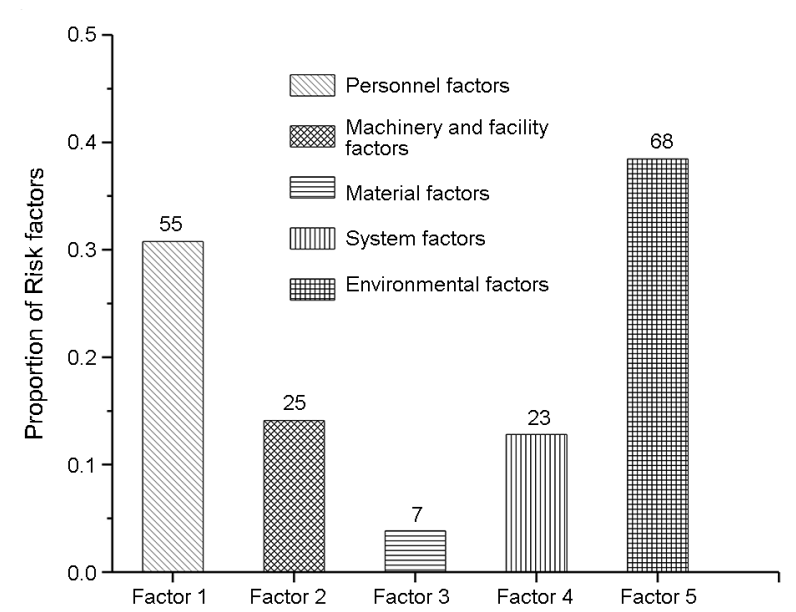

(b)

Figure 3. Risk factors analysis: (a) categories and percentages of subway construction accidents;

(b) causes and associated percentages of subway construction accidents

Table 2. Risk rank and risk acceptance criteria

\begin{tabular}{|c|c|c|c|c|c|c|}
\hline \multirow{3}{*}{\multicolumn{2}{|c|}{$\begin{array}{c}\text { Frequency rank } \\
\text { Disastrous }\end{array}$}} & \multicolumn{5}{|c|}{ Loss rank } \\
\hline & & A & $\mathrm{B}$ & $\mathrm{C}$ & $\mathrm{D}$ & $\mathrm{E}$ \\
\hline & & Very serious & Serious & Considerable & Negligible & \\
\hline 1 & Frequent & $\mathrm{I}$ & $\mathrm{I}$ & $\mathrm{I}$ & II & III \\
\hline 2 & Possible & $\mathrm{I}$ & $\mathrm{I}$ & II & III & III \\
\hline 3 & Occasional & $\mathrm{I}$ & II & III & III & IV \\
\hline 4 & Infrequent & II & III & III & IV & IV \\
\hline 5 & Impossible & III & III & IV & IV & IV \\
\hline Rank & $\begin{array}{c}\text { Risk acceptance } \\
\text { criteria }\end{array}$ & \multicolumn{2}{|c|}{ Disposal principle } & \multicolumn{2}{|c|}{ Control plan } & $\begin{array}{l}\text { Response } \\
\text { department }\end{array}$ \\
\hline I & Unacceptable & \multicolumn{2}{|c|}{$\begin{array}{l}\text { Risk control measures must be } \\
\text { implemented to reduce risk. The risk } \\
\text { should be reduced to acceptable levels or } \\
\text { negligible levels. }\end{array}$} & \multicolumn{2}{|c|}{$\begin{array}{l}\text { The risk warning and the emergency } \\
\text { response plan should be prepared or } \\
\text { revised and adjusted. }\end{array}$} & \multirow{2}{*}{$\begin{array}{l}\text { Government } \\
\text { authorities } \\
\text { and } \\
\text { Construction } \\
\text { parties }\end{array}$} \\
\hline II & Unwanted & \multicolumn{2}{|c|}{$\begin{array}{l}\text { Risk management should be implemented } \\
\text { to reduce risk, and the cost of risk } \\
\text { reduction should not exceed the loss } \\
\text { caused by the risk. }\end{array}$} & \multicolumn{2}{|c|}{$\begin{array}{l}\text { Risk prevention and monitoring and } \\
\text { risk management measures should be } \\
\text { implemented. }\end{array}$} & \\
\hline III & Acceptability & \multicolumn{2}{|c|}{$\begin{array}{l}\text { Implementing risk management and taking } \\
\text { management measures. }\end{array}$} & \multicolumn{2}{|c|}{$\begin{array}{l}\text { Strengthen daily management and } \\
\text { monitoring. }\end{array}$} & \multirow{2}{*}{$\begin{array}{l}\text { Construction } \\
\text { parties }\end{array}$} \\
\hline IV & Negligible & \multicolumn{2}{|c|}{ Implementing risk management. } & \multicolumn{2}{|c|}{ Performing daily inspection. } & \\
\hline
\end{tabular}




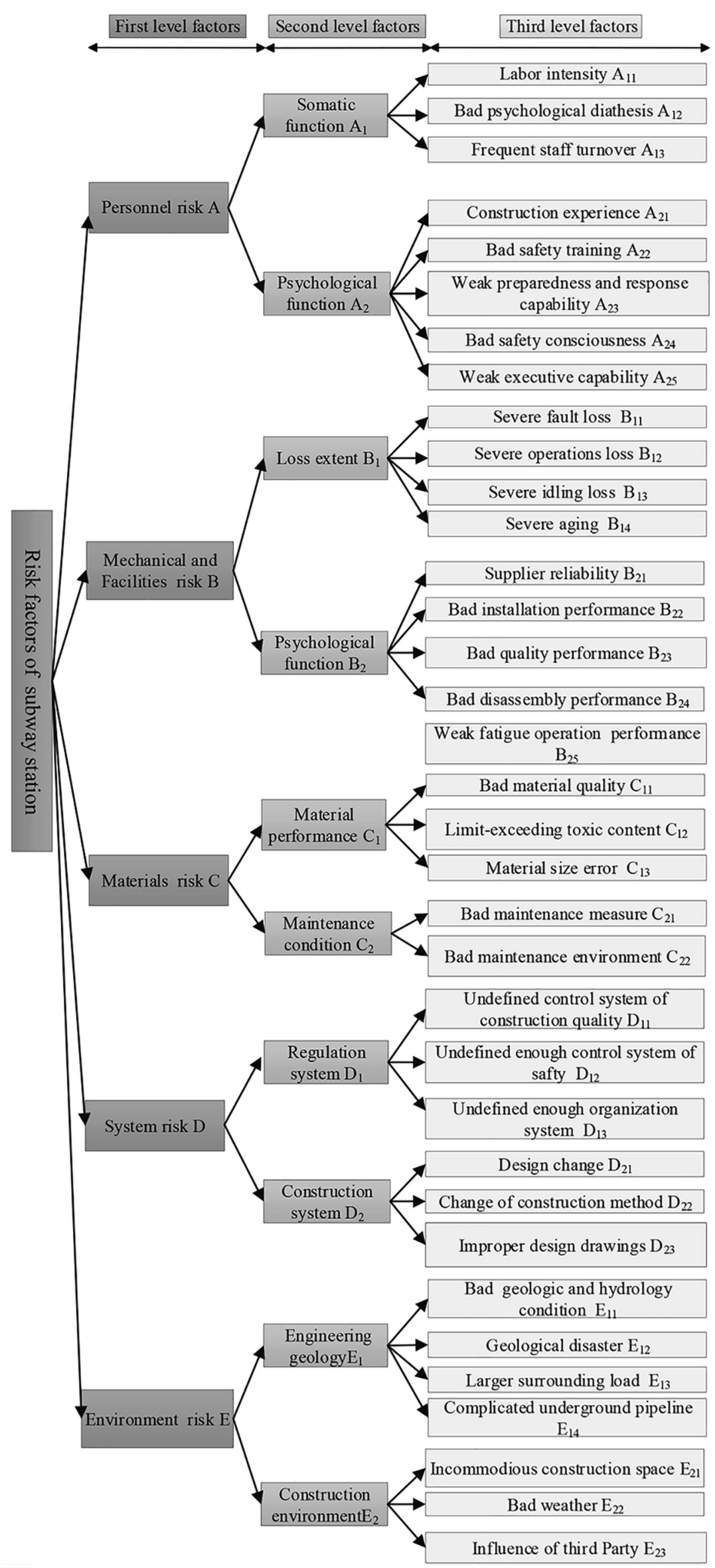

Figure 4. The hierarchical structure of risk factors 


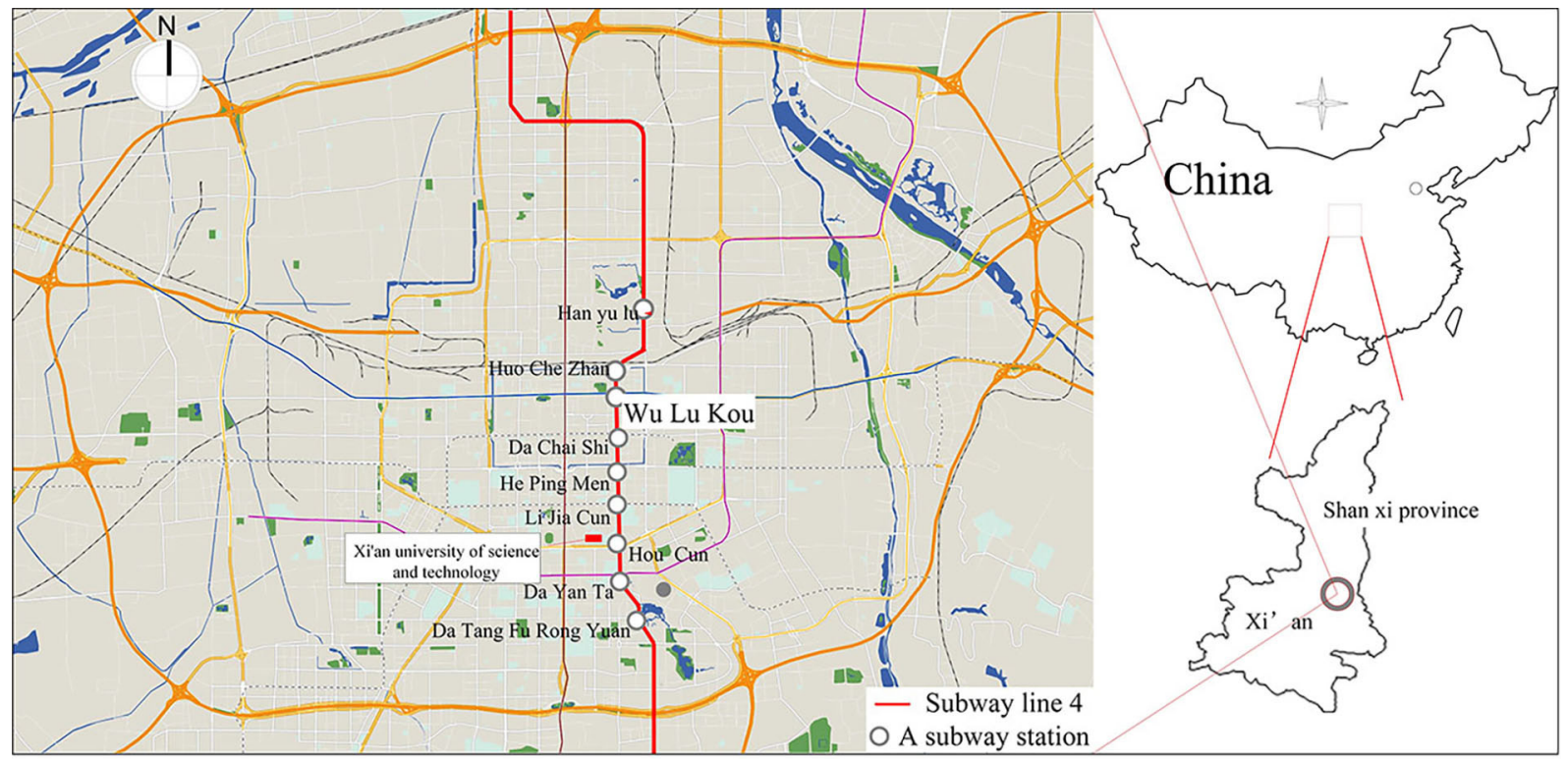

Figure 5. Location of field investigation

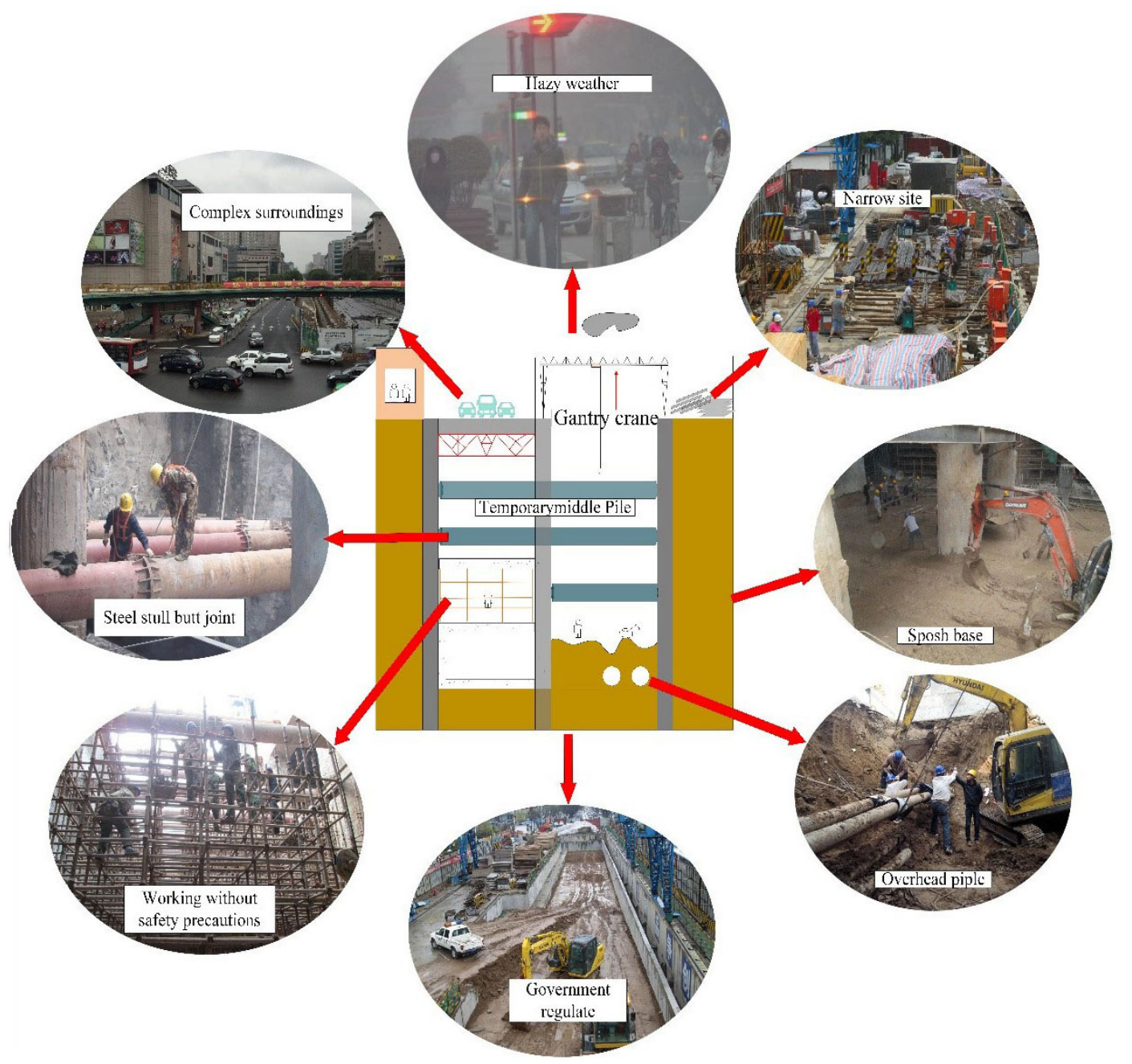

Figure 6. Field investigation of risk events 
occurred risk events in the subway construction. Figure 6 reveals the following partial risk events caused by (1) hazy weather, which can delay the project; (2) the narrow site, which can slow the construction and increase the safety risk and material turnover cost; (3) the rain and lack of drainage capacity, then the loess is changed as flowing soil, which can increase measurement costs and result in delays; (4) pipelines of different types with different orientations and depths, which can increase the measurement cost and result in delays; (5) the government to control the environmental pollution; (6) workers without safety precautions; (7) dangerous operations, such as steel stull butt joint welding and gantry crane operation transported heavy machinery; (8) heavy traffic and numerous tall buildings that surround the site limited construction. These findings help identify risk factors and understand the risk events in subway station construction.

Step 4. Build a network structure of risk factors for subway station construction.

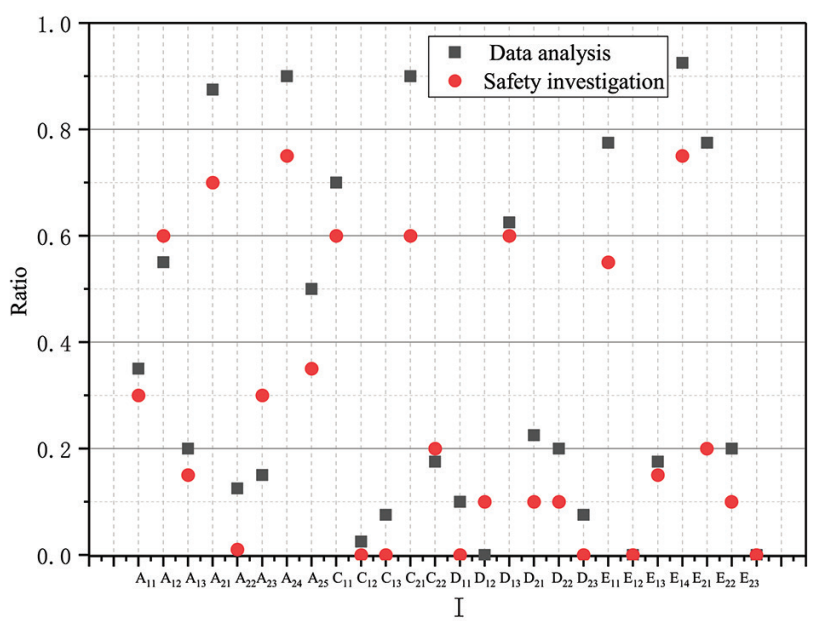

(a)

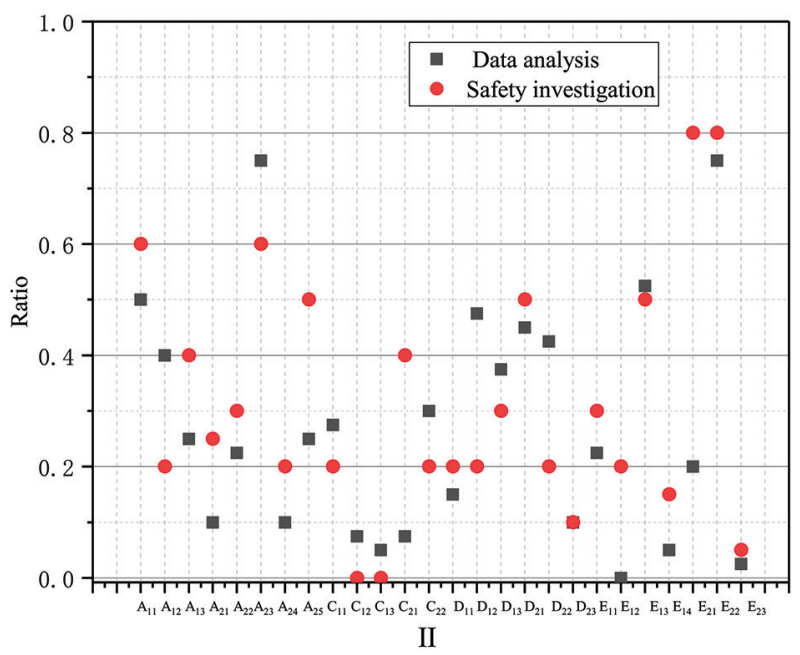

(b)
Engineers and professors in relevant disciplines were selected to complete a questionnaire of field investigation in line with Figure 4 and Table 2. Forty valid questionnaires were collected. Based on the results, the weights of the 25 third-level risk factors were calculated. Figure 7 shows calculation results. Based on the weights (ranks I IV) of the 25 TLRF from the field investigation, risk weights of rank I for most risk factors in the field investigation are slightly smaller than previous estimates, and weight distributions are generally consistent; risk weights of rank II are slightly larger than previous estimates, and weight distributions are generally consistent; risk weight distributions of rank III are generally consistent; and weight distributions of rank IV are slightly different. Therefore, the 25 TLRF are generally suitable as risk factors for subway station projects. Based on the results and safety assessments, risk factors with greater weights, i.e., ranks I and II, are selected to simply the risk factor analysis. Then, the network structure of the FANPCE model is established based on the simpli-

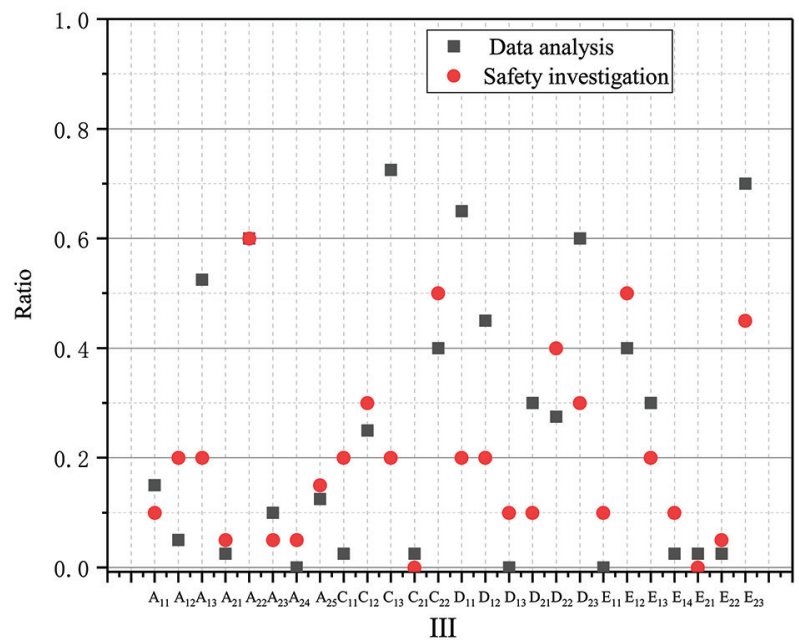

(c)

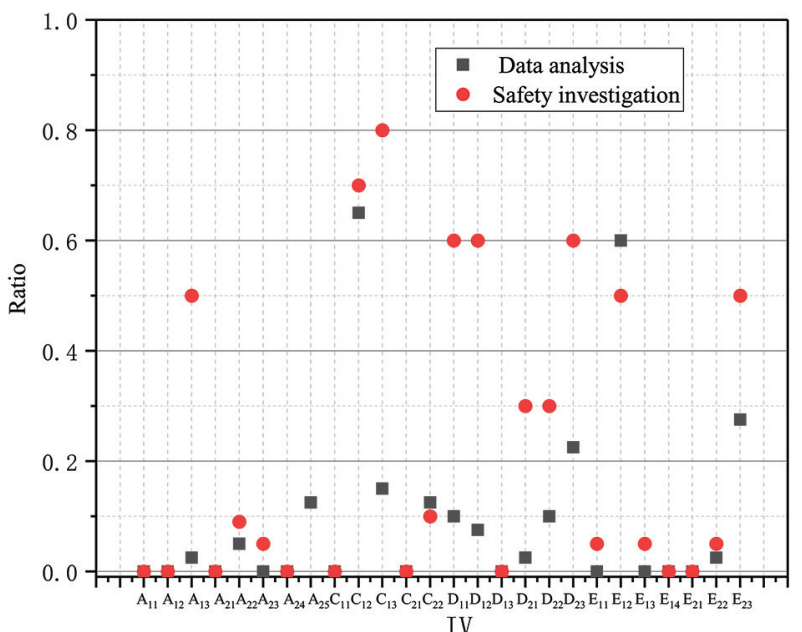

(d)

Figure 7. Results of data analysis and field risk investigation of construction: (a) results of the risk factors weight on risk level I; (b) results of the risk factors weight on risk level II; (c) results of the risk factors weight on risk level III; (d) results of the risk factors weight on risk level IV 


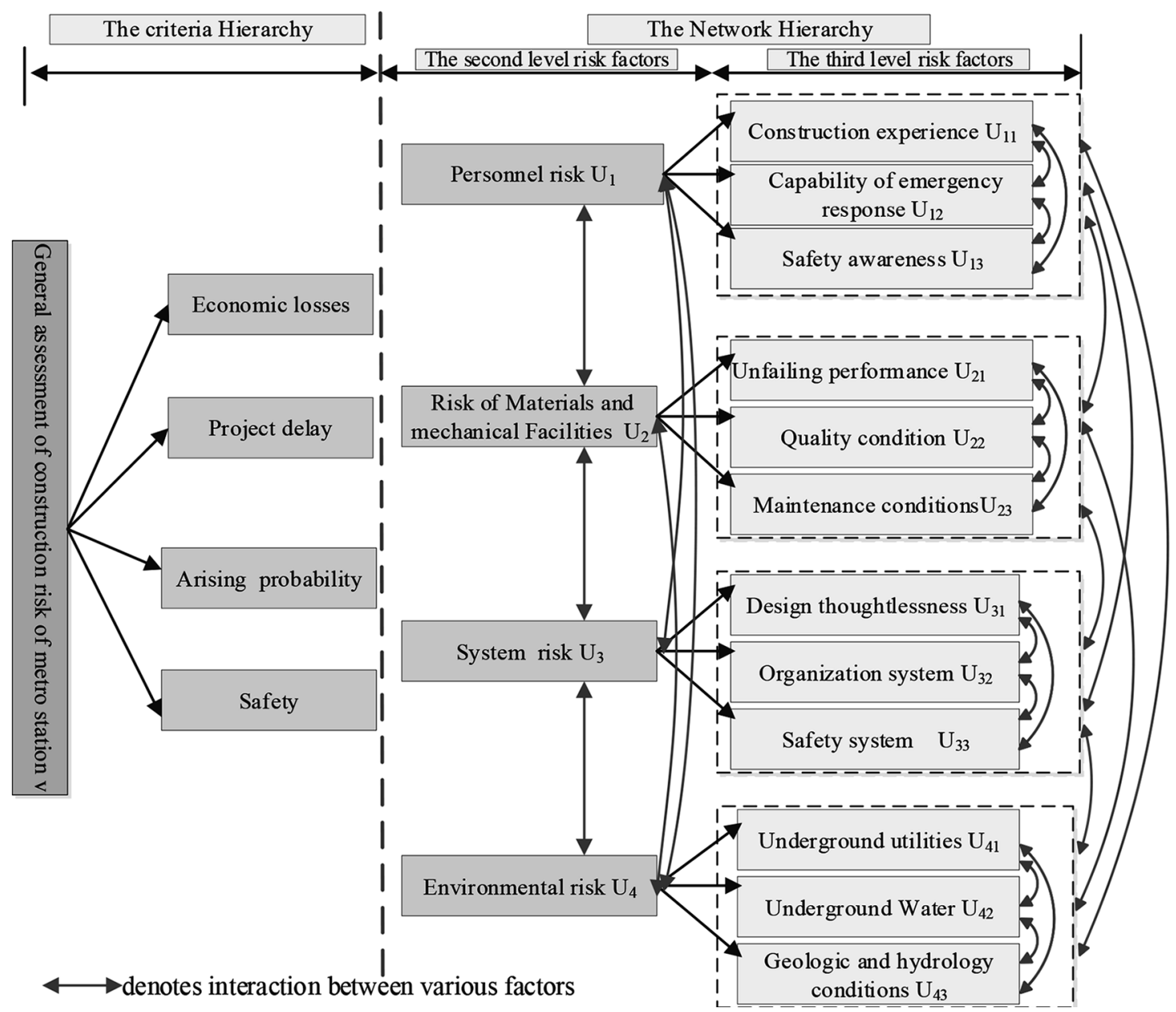

Figure 8. ANP network structure of the risk factors of subway station construction

fied risk factors. Figure 8 illustrates the network structure, which includes a criteria hierarchy and a network hierarchy. Four assessment criteria constitute the criteria hierarchy, and four second risk factors containing twelve TLRF constitute the network hierarchy.

\subsection{Weights}

Step 1. Build a fuzzy relational matrix for a single factor.

Twelve TLRF are evaluated by building a fuzzy relational matrix, which consists of the fuzzy relation from $\mathbf{V}$ to $\mathbf{P}$ corresponding to the probability of generating risk, the loss degree caused by the risk and controllability of the risk based on Table 2. Then, the investigated data are weighted to obtain the fuzzy relational matrix of a single factor $R_{i}$ (Eqn (2)):

$$
\begin{aligned}
\mathbf{R}_{i}= & {\left[\begin{array}{cccc}
R_{(i 1) \mathrm{V}_{\mathrm{I}}} & R_{(i 1) \mathrm{V}_{\mathrm{II}}} & R_{(i 1) \mathrm{V}_{\mathrm{III}}} & R_{(i 1) \mathrm{V}_{\mathrm{IV}}} \\
R_{(i 2) \mathrm{V}_{\mathrm{I}}} & R_{(i 2) \mathrm{V}_{\mathrm{II}}} & R_{(i 2) \mathrm{V}_{\mathrm{III}}} & R_{(i 2) \mathrm{V}_{\mathrm{IV}}} \\
\cdots & \ldots & \cdots & \cdots \\
R_{(i j) \mathrm{V}_{I}} & R_{(i j) \mathrm{V}_{\mathrm{II}}} & R_{(i j) \mathrm{V}_{\mathrm{III}}} & R_{(i j) \mathrm{V}_{\mathrm{IV}}}
\end{array}\right] } \\
& (i=P, L, C ; j=1,2,3 \ldots \ldots),
\end{aligned}
$$

where $j$ is the number of TLRF. Taking the probability of generating risk, the loss degree and the controllability of the risk as criteria, $R_{(i j) \mathrm{V}_{\mathrm{I}}}$ consists of weights of each TLRF at risk level I; $R_{(i j) \mathrm{V}_{\text {II }}}$ consists of weights of each TLRF at level II; $R_{(i j) \mathrm{V}_{\mathrm{III}}}$ consists of weights of each TLRF at risk level III; $R_{(i j) \mathrm{V}_{\mathrm{IV}}}$ consists of weights of each TLRF at risk level IV. Taking the probability of generating risk as an assessment criterion, $\mathbf{R}_{p}$ is the fuzzy relational matrix, and the relevant data is provided from the survey; $\mathbf{R}_{L}$ and $\mathbf{R}_{C}$ are the obtained fuzzy relational matrices based on the loss degree and controllability of the risk. $\mathbf{R}_{L}, \mathbf{R}_{C}$, and $\mathbf{R}_{p}$ are integrated to obtain the weight matrix $\mathbf{R}$, where $\mathbf{R}=1 / 3\left(\mathbf{R}_{L}+\mathbf{R}_{C}+\mathbf{R}_{p}\right)$.

Step 2. Calculate the weight vector of risk factors.

Step 2.1. Build a FCM.

Interactional relationships among the ANP levels are assessed in line with the opinions of experts and engineers; however, the respondents' opinions are vague and unquantifiable. Here, the TFN method is used to address this issue. Dispersion membership is used to evaluate the object, the membership function of relative importance is represented in Table 4. First, the FCMs among twelve TLRFs are built. The factor $\mathrm{U}_{12}$ is taken as the criterion, the incidences of $U_{11}, U_{12}$ and $U_{13}$ for $U_{12}$ are compared for 
Table 3. FCM $\left(\mathbf{B}_{i j}^{12}=\left\{l_{i j}, m_{i j}, u_{i j}\right\}\right)$

\begin{tabular}{|c|c|c|c|c|}
\hline $\mathrm{U}_{12}$ & $\mathrm{U}_{11}$ & $\mathrm{U}_{12}$ & $\mathrm{U}_{13}$ & Weight \\
\hline $\mathrm{U}_{11}$ & $(1,1,1)$ & $\left(l_{12}, m_{12}, u_{12}\right)$ & $\left(l_{13}, m_{13}, u_{13}\right)$ & $w_{12}^{1}$ \\
\hline $\mathrm{U}_{12}$ & $\left(l_{21}, m_{21}, u_{21}\right)$ & $(1,1,1)$ & $\left(l_{23}, m_{23}, u_{23}\right)$ & $w_{12}^{2}$ \\
\hline $\mathrm{U}_{13}$ & $\left(l_{31}, m_{31}, u_{31}\right)$ & $\left(l_{32}, m_{32}, u_{32}\right)$ & $(1,1,1)$ & $w_{12}^{3}$ \\
\hline
\end{tabular}

relative significance, and the result is presented by TFN $(l$, $m, n)$. Second, based on the result, FCM $\mathbf{B}_{i j}^{12}=\left(l_{i j}, m_{i j}, u_{i j}\right)$; $l_{i j} \leq m_{i j} \leq u_{i j} ; i, j=1,2,3$ is built, as shown in Table 3 , where $l_{i j}, m_{i j}, u_{i j}$ can be determined by experts and engineers of relevant disciplines (Zimmerman, 2001; Tang \& Beynon, 2005). Third, factors $U_{12}$ and $U_{13}$ are taken as the criterion, the incidences, $\mathrm{U}_{11}, \mathrm{U}_{12}$ and $\mathrm{U}_{13}$ for $\mathrm{U}_{12}$ and $\mathrm{U}_{13}$ are compared to obtain the relative significance and build the FCMs $\left(\mathbf{B}_{i j}^{11}\right.$ and $\mathbf{B}_{i j}^{13}$ ).

In the factor set $U_{2}$, risk factors $\left(U_{21}, U_{22}, U_{23}\right)$ are taken as the criteria, the relative importance of $\mathrm{U}_{11}, \mathrm{U}_{12}$, and $\mathrm{U}_{13}$ is examined to build the FCMs $\left(\mathbf{C}_{i j}^{11}, \mathbf{C}_{i j}^{12}, \mathbf{C}_{i j}^{13}\right)$. In the same way, in the factor set $U_{2}, U_{3}$ and $U_{4}$, risk factors $\left(\mathrm{U}_{21}, \mathrm{U}_{22}, \mathrm{U}_{23}\right),\left(\mathrm{U}_{31}, \mathrm{U}_{32}, \mathrm{U}_{33}\right)$, and $\left(\mathrm{U}_{41}, \mathrm{U}_{42}, \mathrm{U}_{43}\right)$ are taken as the criteria, the relative importance of $\mathrm{U}_{11}$, $\mathrm{U}_{12}$ and $\mathrm{U}_{13}$ is compared to build the FCMs $\left(\mathbf{C}_{i j}^{11}, \mathbf{C}_{i j}^{12}\right.$, $\left.\mathbf{C}_{i j}^{13}\right),\left(\mathbf{D}_{i j}^{11}, \mathbf{D}_{i j}^{12}, \mathbf{D}_{i j}^{13}\right)$ and $\left(\mathbf{E}_{i j}^{11}, \mathbf{E}_{i j}^{12}, \mathbf{E}_{i j}^{13}\right)$, respectively; the FCMs $\left(\mathbf{B}_{i j}^{21}, \mathbf{B}_{i j}^{22}, \mathbf{B}_{i j}^{23}\right),\left(\mathbf{C}_{i j}^{21}, \mathbf{C}_{i j}^{22}, \mathbf{C}_{i j}^{23}\right),\left(\mathbf{D}_{i j}^{21}\right.$, $\left.\mathbf{D}_{i j}^{22}, \mathbf{D}_{i j}^{23}\right),\left(\mathbf{E}_{i j}^{21}, \mathbf{E}_{i j}^{22}, \mathbf{E}_{i j}^{23}\right),\left(\mathbf{B}_{i j}^{31}, \mathbf{B}_{i j}^{32}, \mathbf{B}_{i j}^{33}\right),\left(\mathbf{C}_{i j}^{31}, \mathbf{C}_{i j}^{32}\right.$, $\left.\mathbf{D}_{i j}^{22}, \mathbf{D}_{i j}^{23}\right),\left(\mathbf{E}_{i j}^{21}, \mathbf{E}_{i j}^{23}, \mathbf{E}_{i j}^{3 j}\right),\left(\mathbf{B}_{i j}^{3 j}, \mathbf{B}_{i j}^{32}, \mathbf{B}_{i j}^{3 j}\right),\left(\mathbf{C}_{i j}^{31}, \mathbf{C}_{i j}^{3 j}\right.$,
$\left.\mathbf{C}_{i j}^{33}\right),\left(\mathbf{D}_{i j}^{31}, \mathbf{D}_{i j}^{32}, \mathbf{D}_{i j}^{33}\right),\left(\mathbf{E}_{i j}^{31}, \mathbf{E}_{i j}^{32}, \mathbf{E}_{i j}^{33}\right),\left(\mathbf{B}_{i j}^{41}, \mathbf{B}_{i j}^{42}, \mathbf{B}_{i j}^{43}\right)$, $\left(\mathbf{C}_{i j}^{41}, \mathbf{C}_{i j}^{42}, \mathbf{C}_{i j}^{43}\right),\left(\mathbf{D}_{i j}^{41}, \mathbf{D}_{i j}^{42}, \mathbf{D}_{i j}^{43}\right)$, and $\left(\mathbf{E}_{i j}^{41}, \mathbf{E}_{i j}^{42}\right.$, $\mathbf{E}_{i j}^{43}$ ) can be obtained in the same way.

Step 2.2. Calculate the fuzzy weight sector of FCMs.

In the weight decision analysis, the cut set of fuzzy analysis is used to remove the fuzziness of the weight (E. Akyar, H. Akyar, \& Duzce, 2012). The following assumptions are made:

$$
\begin{aligned}
& w_{i}=\left(w_{i}^{L} w_{i}^{M} w_{i}^{S}\right), \\
& w_{i}^{L}(\alpha)=\left(w_{i}^{M}-w_{i}^{L}\right) \alpha+w_{i}^{L}, \\
& w_{i}^{S}(\alpha)=\left(w_{i}^{S}-w_{i}^{M}\right) \alpha+w_{i}^{M} .
\end{aligned}
$$

By integrating Eqns (3), (4), Eqns (5) and (6) can be obtained:

$$
w_{i}(\alpha, \lambda)=\lambda w_{i}^{S}(\alpha)+(1-\lambda) w_{i}^{L}(\alpha),
$$

where the cut parameter $\alpha$, ranging from $[0,1]$, represents the optimistic scope of the weight of judgment of experts (Zimmerman, 2001). Because the comments of each expert are valid, then $\alpha=0$. The parameter $\lambda$, ranging from $[0,1]$, represents the optimistic range of the weight of expert judgment suggestions (Feng, 2006; Shin et al., 2016). Due to the conservative attitude of each expert, then $\lambda=1$. Based on this analysis, the fuzzy weight vector is calculated by the following equation: $w_{i}(\alpha, \lambda)=w_{i}^{S}(\alpha)=w_{i}^{M}$. Then, the fuzzy weight vector $\left\{\begin{array}{llll}w_{12}^{1} & w_{12}^{2} & w_{12}^{3}\end{array}\right\}^{T}$ of the FCM $\mathbf{B}_{i j}^{12}$ is calculated by the characteristic root method. Fur- thermore, the fuzzy weight vector $\left\{w_{12}^{1} w_{12}^{2} w_{12}^{3}\right\}^{T}$ is also the priority vector of the effect of $\mathrm{U}_{11}, \mathrm{U}_{12}$ and $\mathrm{U}_{13}$ on $\mathrm{U}_{12}$. At the same time, the weight vector $\left\{w_{11}^{1} w_{11}^{2} w_{11}^{3}\right\}^{T}$ of $\mathbf{B}_{i j}^{11}$ and $\left\{w_{13}^{1} w_{13}^{2} w_{13}^{3}\right\}^{T}$ of $\mathbf{B}_{i j}^{13}$ are calculated. Next, the FWM $\mathbf{W}_{11}^{B}$ (Eqn (7)) of the factor set $\mathrm{U}_{1}$ can be obtained by combining $\left\{w_{12}^{1} w_{12}^{2} w_{12}^{3}\right\}^{T},\left\{w_{11}^{1} w_{11}^{2} w_{11}^{3}\right\}^{T}$, and $\left\{w_{13}^{1} w_{13}^{2} w_{13}^{3}\right\}^{T}$.

$$
\mathbf{W}_{11}^{B}=\left[\begin{array}{lll}
w_{11}^{1} & w_{12}^{1} & w_{13}^{1} \\
w_{11}^{1} & w_{12}^{1} & w_{13}^{1} \\
w_{11}^{1} & w_{12}^{1} & w_{13}^{1}
\end{array}\right]
$$

The calculation is repeated in the same way, the FWMs of $\mathbf{W}_{12}^{C}, \mathbf{W}_{13}^{D}, \mathbf{W}_{14}^{E}, \mathbf{W}_{21}^{B}, \mathbf{W}_{22}^{C}, \mathbf{W}_{23}^{D}, \mathbf{W}_{24}^{E}, \mathbf{W}_{31}^{B}, \mathbf{W}_{32}^{C}$, $\mathbf{W}_{33}^{D}, \mathbf{W}_{34}^{E}, \mathbf{W}_{41}^{B}, \mathbf{W}_{42}^{C}, \mathbf{W}_{43}^{D}$, and $\mathbf{W}_{44}^{E}$ are obtained according to calculation of the weight sectors of FCMs $\left(\mathbf{C}_{i j}^{11}, \mathbf{C}_{i j}^{12}, \mathbf{C}_{i j}^{13}\right),\left(\mathbf{D}_{i j}^{11}, \mathbf{D}_{i j}^{12}, \mathbf{D}_{i j}^{13}\right),\left(\mathbf{E}_{i j}^{11}, \mathbf{E}_{i j}^{12}, \mathbf{E}_{i j}^{13}\right)$, $\left(\mathbf{B}_{i j}^{21}, \mathbf{B}_{i j}^{22}, \mathbf{B}_{i j}^{23}\right),\left(\mathbf{C}_{i j}^{21}, \mathbf{C}_{i j}^{22}, \mathbf{C}_{i j}^{23^{i j}}\right),\left(\mathbf{D}_{i j}^{21}, \mathbf{D}_{i j}^{22}, \mathbf{D}_{i j}^{23}\right)$, $\left(\mathbf{E}_{i j}^{21}, \mathbf{E}_{i j}^{22}, \mathbf{E}_{i j}^{23}\right),\left(\mathbf{B}_{i j}^{31}, \mathbf{B}_{i j}^{32}, \mathbf{B}_{i j}^{33}\right),\left(\mathbf{C}_{i j}^{31}, \mathbf{C}_{i j}^{32}, \mathbf{C}_{i j}^{33}\right),\left(\mathbf{D}_{i j}^{31}\right.$, $\left.\mathbf{D}_{i j}^{32}, \mathbf{D}_{i j}^{33}\right),\left(\mathbf{E}_{i j}^{31}, \mathbf{E}_{i j}^{32}, \mathbf{E}_{i j}^{33}\right),\left(\mathbf{B}_{i j}^{41}, \mathbf{B}_{i j}^{42^{2}}, \mathbf{B}_{i j}^{4 j}\right),\left(\mathbf{C}_{i j}^{41}\right.$, $\left.\mathbf{C}_{i j}^{42}, \mathbf{C}_{i j}^{43}\right),\left(\mathbf{D}_{i j}^{41}, \mathbf{D}_{i j}^{42}, \mathbf{D}_{i j}^{43}\right)$, and $\left(\mathbf{E}_{i j}^{41}, \mathbf{E}_{i j}^{42}, \mathbf{E}_{i j}^{43}\right)$.

The FWMs are combined to constitute the unweighted fuzzy super matrix W (Eqn (8)).

$$
\mathbf{W}=\left[\begin{array}{rrrr}
\mathbf{W}_{11}^{B} & \mathbf{W}_{12}^{B} & \mathbf{W}_{13}^{B} & \mathbf{W}_{14}^{B} \\
\mathbf{W}_{21}^{C} & \mathbf{W}_{22}^{C} & \mathbf{W}_{23}^{C} & \mathbf{W}_{24}^{C} \\
\mathbf{W}^{D} & \mathbf{W}_{32}^{D} & \mathbf{W}_{33}^{D} & \mathbf{W}_{34}^{D} \\
\mathbf{W}^{E} & \mathbf{W}_{42}^{E} & \mathbf{W}_{43}^{E} & \mathbf{W}_{44}^{E}
\end{array}\right]
$$

Step 2.3. Build the fuzzy weight matrix of elements of second-level factors.

Since the fuzzy super matrix $\mathbf{W}$ is not normalized, the calculation of the weight of subblock $\mathbf{W}_{i j}$ of super matrix $\mathbf{W}$ is necessary. The pairwise blocks are compared to build the FCM, so as to obtain the normalized sort vector $\mathbf{A}$ per subblock $\mathbf{W}_{i j} \cdot a_{i j}$ represents the weight of sub-block $i$ and $i$ affects sub-block $j$, and $a_{i j}=0$ indicates there is no effect. As the method in step 2, taking risk factors $U_{1}, U_{2}, U_{3}$, and $\mathrm{U}_{4}$ as the criteria, the relative importance of $\mathrm{U}_{1}, \mathrm{U}_{2}$, $\mathrm{U}_{3}$, and $\mathrm{U}_{4}$ is compared to build FCMs $\left(\mathbf{F}_{i j}^{1}, \mathbf{F}_{i j}^{2}, \mathbf{F}_{i j}^{3}, \mathbf{F}_{i j}^{4}\right)$. Then, FWM A of FCMs $\left(\mathbf{F}_{i j}^{1}, \mathbf{F}_{i j}^{2}, \mathbf{F}_{i j}^{3}, \mathbf{F}_{i j}^{4}\right)$ is calculated.

$$
\mathbf{A}=\left[\begin{array}{llll}
a_{11} & a_{12} & a_{13} & a_{14} \\
a_{21} & a_{22} & a_{23} & a_{24} \\
a_{31} & a_{32} & a_{33} & a_{34} \\
a_{41} & a_{42} & a_{43} & a_{44}
\end{array}\right]
$$


The fuzzy weighted super matrix $\underline{\mathbf{W}}$ (Eqn (10)) can be built based on the fuzzy super matrix $\mathbf{W}$ and the FWM A :

$$
\underline{\mathbf{W}}=\mathbf{A} \times \mathbf{W}=\left[\begin{array}{rrrr}
a_{11} \mathbf{W}_{11}^{B} & a_{12} \mathbf{W}_{12}^{B} & a_{13} \mathbf{W}_{13}^{B} & a_{14} \mathbf{W}^{B} \\
a_{21} \mathbf{W}_{21}^{C} & a_{22} \mathbf{W}_{22}^{C} & a_{23} \mathbf{W}_{23}^{C} & a_{24} \mathbf{W}_{24}^{C} \\
a_{31} \mathbf{W}^{D} & a_{32} \mathbf{W}_{32}^{D} & a_{33} \mathbf{W}^{D} & a_{34} \mathbf{W}_{34}^{D} \\
a_{41} \mathbf{W}_{41}^{E} & a_{42} \mathbf{W}_{42}^{E} & a_{43} \mathbf{W}^{E} & a_{44} \mathbf{W}_{44}^{E}
\end{array}\right]
$$

\subsection{Calculation of the limit order sector}

The limit order sector $\mathbf{T}$ can be obtained by multiplying it with itself until the normalization eigenvector of the super matrix $\mathbf{W}$ corresponds to the eigenvalue 1 with Eqn (11) (Saaty, 2004; Dağdeviren et al., 2008; Tavana et al., 2013).

$$
\mathbf{T}=\lim _{n \rightarrow \infty} \mathbf{W}^{n},
$$

where $\mathbf{T}$ is the limit order sector; $\mathbf{W}$ is the weighted super matrix; $n$ is the exponent determined by iteration. The final priorities of risk factors can be shown in the corresponding columns in the limit order sector.

\subsection{Assessment on the risk level of construction}

The construction risk level of the project is assessed through the FCE model in Eqn (12):

$$
\mathbf{V}=\mathbf{T} \text { o } \mathbf{R},
$$

where $\mathbf{V}$ represents the evaluation result vector, which is the description of the comprehensive risk level of evaluation projects; $\mathbf{R}$ represents fuzzy relation matrix, and the evaluation result of single risk factor; $\mathbf{T}$ represents the evaluate weight vector of the risk factor obtained through FANPCE, describing the relative importance of risk factors toward the evaluation object; $\bigcirc$ represents a fuzzy synthesis operator, synthesizing $\mathbf{T}$ and $\mathbf{R}$. In addition, the multiplication and bounded operator $\mathrm{M}(\bullet, \oplus)$ of fuzzy mathematics operation theory are adopted (Dai \& Li, 2016). The formula describes that fuzzy relations $\mathbf{T}$ of evaluation risk factors and evaluation projects are transformed into the fuzzy relationship $\mathbf{V}$ between the evaluated project and the evaluation grade through fuzzy transducer $\mathbf{R}$, which represents the fuzzy relation of the evaluation risk factors and the evaluation risk level. The comprehensive evaluation matrix $\mathbf{V}$ can be determined by Eqn (12) and by acquiring the value of $\underset{1 \leq i \leq n}{\operatorname{Max}}\left(v_{i} / \sum_{i=1}^{n} v_{i}\right)$ (maximum membership) (Saaty, 2004; Wang \& HakKeung, 2018), which is the evaluation of the model.

\section{Case study}

\subsection{Project backgrounds}

$\mathrm{Wu} \mathrm{Lu}$ Kou station is a transfer station between subway line 1 and subway line 4 in Xian. The location of the station is shown in Figure 5. The average excavation depth of the foundation pit is $23.1 \mathrm{~m}$, and the main volume of the foundation pit is $83273 \mathrm{~m}^{3}$. The construction structure of the station involves bored piles, internal supports, temporary central piles and temporary cover systems which comprise prefabricated steel girders. These components constitute a complex and narrow construction space, resulting in a high probability of risk events, as shown in Figure 6. Therefore, investigating the construction risk is necessary for subway station project to improve the efficiency. The total construction risk of this subway station was assessed by the FANPCE method on 12/2013.

\subsection{Results and analysis}

Twenty engineers of relevant disciplines associated with the Wu Lu Kou station were selected to evaluate the subelements based on a comment set and Table 2. The investigated sub-element results in line with the probability of generating risk are presented in Table 3. By weighting the data in Table 3, the fuzzy relational matrix $\mathbf{R}_{P}$ is built, as described in this section. In the same way, the fuzzy relational matrices $\mathbf{R}_{L}$ and $\mathbf{R}_{C}$ can be obtained. Finally, the matrices $\mathbf{R}_{L}, \mathbf{R}_{C}$, and $\mathbf{R}_{P}$ are integrated to obtain the weight matrix $\mathbf{R}$. These results are presented as follows:

$$
\mathbf{R}_{P}=\left|\begin{array}{cccc}
0.65 & 0.25 & 0.05 & 0.05 \\
0.55 & 0.35 & 0.05 & 0 \\
0.6 & 0.35 & 0.05 & 0 \\
0.05 & 0.05 & 0.5 & 0.4 \\
0.05 & 0.1 & 0.35 & 0.5 \\
0.3 & 0.3 & 0.2 & 0.2 \\
0 & 0.05 & 0.3 & 0.65 \\
0.3 & 0.4 & 0.1 & 0.2 \\
0.1 & 0.2 & 0.6 & 0.1 \\
0.4 & 0.4 & 0.1 & 0.1 \\
0.7 & 0.2 & 0.1 & 0 \\
0.25 & 0.3 & 0.4 & 0.05
\end{array}\right|, \mathbf{R}_{C}=\left|\begin{array}{cccc}
0.7 & 0.15 & 0.15 & 0 \\
0.65 & 0.2 & 0.15 & 0 \\
0.8 & 0.1 & 0.05 & 0.05 \\
0.1 & 0.25 & 0.4 & 0.25 \\
0.15 & 0.45 & 0.3 & 0.1 \\
0.45 & 0.5 & 0 & 0.05 \\
0.05 & 0.2 & 0.35 & 0.4 \\
0.4 & 0.4 & 0.2 & 0 \\
0.05 & 0.05 & 0.8 & 0.1 \\
0.5 & 0.4 & 0 & 0.1 \\
0.5 & 0.3 & 0.1 & 0.1 \\
0.5 & 0.3 & 0.1 \\
0.35 & 0.05 & 0.2 & 0.4
\end{array}\right|,
$$

The fuzzy relational matrix $\mathrm{R}$ of a single factor reveals that, the risk rank I weights of 12 TLRF are ordered as $\mathrm{U}_{11}>\mathrm{U}_{13}>\mathrm{U}_{42}>\mathrm{U}_{12}>\mathrm{U}_{32}>\mathrm{U}_{41}>\mathrm{U}_{43}>\mathrm{U}_{23}>\mathrm{U}_{22}>\mathrm{U}_{21}$ $=\mathrm{U}_{33}>\mathrm{U}_{31}$, and the risk factors (construction experience, safety awareness, and underground water) are considered as high-risk factors of the single assessed factors. The risk 
rank II weights of 12 TLRF is ordered as $\mathrm{U}_{23}>\mathrm{U}_{41}>\mathrm{U}_{22}>$ $\mathrm{U}_{32}>\mathrm{U}_{12}=\mathrm{U}_{13}>\mathrm{U}_{42}>\mathrm{U}_{43}>\mathrm{U}_{21}>\mathrm{U}_{31}>\mathrm{U}_{11}>\mathrm{U}_{33}$, and the underground utilities and maintenance conditions of materials are more sensitive risk factors. The risk rank III weights of 12 TLRF is ordered as $\mathrm{U}_{33}>\mathrm{U}_{21}>\mathrm{U}_{31}>\mathrm{U}_{43}>$ $\mathrm{U}_{22}>\mathrm{U}_{12}>\mathrm{U}_{32}>\mathrm{U}_{31}>\mathrm{U}_{41}=\mathrm{U}_{42}>\mathrm{U}_{11}>\mathrm{U}_{13}$, and the safety system and unfailing performance are more sensitive risk factors. The risk rank IV weights of 12 TLRF is ordered as $\mathrm{U}_{31}>\mathrm{U}_{33}>\mathrm{U}_{21}>\mathrm{U}_{22}>\mathrm{U}_{43}>\mathrm{U}_{41}=\mathrm{U}_{23}>\mathrm{U}_{32}>$ $\mathrm{U}_{42}>\mathrm{U}_{11}=\mathrm{U}_{12}=\mathrm{U}_{13}$, and the design thoughtlessness and safety system are more sensitive risk factors.

Next, the results of the FWMs are as follows:

$$
\mathbf{W}=\left[\begin{array}{llllllllllll}
0.3230 & 0.0759 & 0.1775 & 0.6370 & 0.2351 & 0.6000 & 0.6000 & 0.3420 & 0.4934 & 0.5499 & 0.6337 & 0.2846 \\
0.1104 & 0.7258 & 0.5190 & 0.1047 & 0.1130 & 0.2000 & 0.2000 & 0.1339 & 0.1958 & 0.2402 & 0.1744 & 0.3668 \\
0.5666 & 0.1983 & 0.3035 & 0.2583 & 0.6519 & 0.2000 & 0.2000 & 0.5241 & 0.3108 & 0.2098 & 0.1919 & 0.3486 \\
0.5134 & 0.1037 & 0.2158 & 0.6854 & 0.3236 & 0.4806 & 0.2970 & 0.6118 & 0.2872 & 0.5525 & 0.2297 & 0.6354 \\
0.2567 & 0.2470 & 0.6817 & 0.2344 & 0.6018 & 0.1140 & 0.1634 & 0.1789 & 0.6348 & 0.3329 & 0.6483 & 0.2716 \\
0.2299 & 0.6223 & 0.1025 & 0.0802 & 0.0746 & 0.4054 & 0.5396 & 0.2092 & 0.0780 & 0.1146 & 0.1220 & 0.0929 \\
0.2493 & 0.2098 & 0.6250 & 0.5277 & 0.0980 & 0.1700 & 0.0962 & 0.1884 & 0.1775 & 0.1700 & 0.1020 & 0.5782 \\
0.5936 & 0.5499 & 0.2385 & 0.2274 & 0.4914 & 0.7074 & 0.3519 & 0.7306 & 0.5190 & 0.7074 & 0.7258 & 0.2627 \\
0.1571 & 0.2402 & 0.1365 & 0.2449 & 0.4106 & 0.1226 & 0.5519 & 0.0810 & 0.3035 & 0.1226 & 0.1721 & 0.1591 \\
0.1365 & 0.1365 & 0.1963 & 0.1350 & 0.1149 & 0.3275 & 0.1634 & 0.1307 & 0.3220 & 0.4489 & 0.1336 & 0.1048 \\
0.6250 & 0.6250 & 0.6571 & 0.2808 & 0.1210 & 0.2599 & 0.5396 & 0.2470 & 0.1463 & 0.3690 & 0.7471 & 0.4991 \\
0.2385 & 0.2385 & 0.1466 & 0.5842 & 0.7641 & 0.4126 & 0.2970 & 0.6223 & 0.5317 & 0.1820 & 0.1194 & 0.3961
\end{array}\right] .
$$

The FWM of the elements of the second-level factor $\mathbf{A}$ and the fuzzy weighted super matrix $\underline{\mathbf{W}}$ are represented as follows:

$\begin{aligned} & =\left[\begin{array}{ccccccccccccc}0.1180 & 0.0296 & 0.0648 & 0.2170 & 0.0801 & 0.2044 & 0.1585 & 0.0904 & 0.1304 & 0.1612 & 0.1858 & 0.0834 \\ 0.0403 & 0.2542 & 0.1895 & 0.0357 & 0.0385 & 0.0681 & 0.0528 & 0.0354 & 0.0517 & 0.0704 & 0.0511 & 0.1075 \\ 0.2069 & 0.0814 & 0.1108 & 0.0880 & 0.2220 & 0.0681 & 0.0528 & 0.1385 & 0.0821 & 0.0615 & 0.0563 & 0.1022 \\ 0.0465 & 0.0118 & 0.0195 & 0.1521 & 0.0718 & 0.1066 & 0.0171 & 0.0353 & 0.0166 & 0.0302 & 0.0126 & 0.0348 \\ 0.0232 & 0.0224 & 0.0617 & 0.0520 & 0.1335 & 0.0253 & 0.0094 & 0.0103 & 0.0366 & 0.0182 & 0.0355 & 0.0149 \\ 0.0208 & 0.0563 & 0.0093 & 0.0178 & 0.0166 & 0.0900 & 0.0311 & 0.0121 & 0.0045 & 0.0063 & 0.0067 & 0.0051 \\ 0.0304 & 0.0256 & 0.0762 & 0.0288 & 0.0053 & 0.0093 & 0.0493 & 0.0966 & 0.0910 & 0.0183 & 0.0110 & 0.0624 \\ 0.0724 & 0.0670 & 0.0291 & 0.0124 & 0.0268 & 0.0386 & 0.1804 & 0.3746 & 0.2661 & 0.0763 & 0.0783 & 0.0283 \\ 0.0192 & 0.0293 & 0.0166 & 0.0133 & 0.0224 & 0.0067 & 0.2830 & 0.0415 & 0.1556 & 0.0132 & 0.0186 & 0.0172 \\ 0.0577 & 0.0577 & 0.0829 & 0.0074 & 0.0063 & 0.0178 & 0.0270 & 0.0216 & 0.0533 & 0.2443 & 0.0727 & 0.0570 \\ 0.2640 & 0.2640 & 0.2776 & 0.0153 & 0.0066 & 0.0142 & 0.0892 & 0.0409 & 0.0242 & 0.2008 & 0.4066 & 0.2717 \\ 0.1007 & 0.1007 & 0.0619 & 0.0318 & 0.0416 & 0.0225 & 0.0491 & 0.1029 & 0.0879 & 0.0991 & 0.0650 & 0.2156\end{array}\right], \\ \mathbf{A} & =\left[\begin{array}{llllll}0.3652 & 0.3406 & 0.2642 & 0.2932 \\ 0.0905 & 0.2219 & 0.0577 & 0.0547 \\ 0.1219 & 0.0545 & 0.5127 & 0.1079 \\ 0.4224 & 0.3831 & 0.1654 & 0.5443\end{array}\right] .\end{aligned}$

The limit order sector $\mathbf{T}$ is as follow:

$\mathbf{T}=\{0.1266,0.0896,0.1076,0.0327,0.0332,0.0172,0.0426,0.1087,0.0388,0.0693,0.2407,0.0930\}^{T}$.

Which is also the final weight of 12 TLRF. The final weights of 12 TLRF are ordered as $\mathrm{U}_{42}>\mathrm{U}_{11}>\mathrm{U}_{32}>\mathrm{U}_{13}>$ $\mathrm{U}_{43}>\mathrm{U}_{12}>\mathrm{U}_{41}>\mathrm{U}_{31}>\mathrm{U}_{33}>\mathrm{U}_{22}>\mathrm{U}_{21}>\mathrm{U}_{23}$. The result reveals that the weight of underground water is the biggest. Therefore, it should be a focal risk factor, whose in- fluence can also be verified in the field risk investigation as shown in the Figure 6 . The rain and lack of drainage capacity made the loess become flowing soil, which increased measurement costs, the delay of the construction and the decrease of the foundation stability. In addition, the con- 


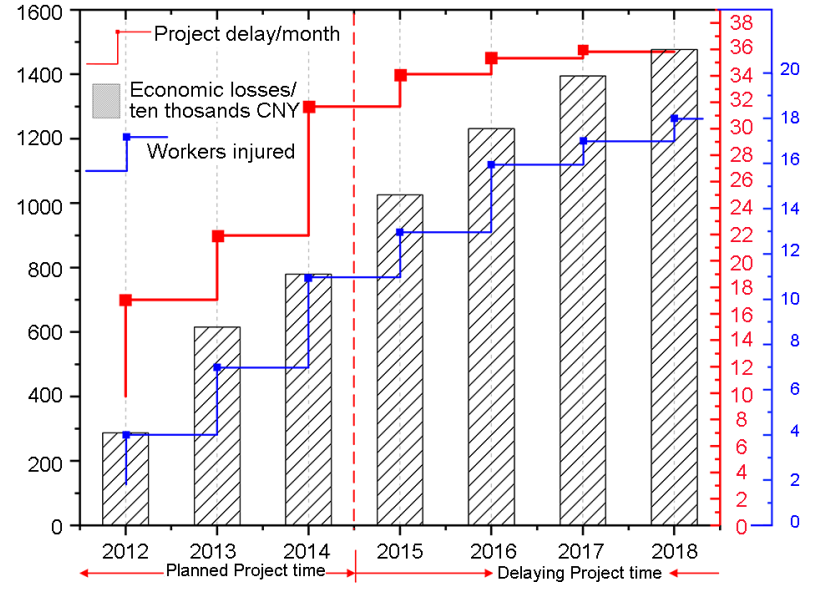

Figure 9. Accumulated losses in the construction

struction, organization system and safety awareness also play important roles in risk events. Meanwhile, the result also reveals that maintenance conditions is the least sensitive parameter in risk events.

Then, based on $\mathbf{V}=\{0.4991,0.2370,0.1642$, $0.1001\}^{T}$, results can be obtained. The weight of rank I is 0.4991 , i.e., the maximum; the weight of rank II is 0.2370 ; the weight of rank III is 0.1642; and the weight of rank IV is 0.1001 . Based on the maximum membership principle that $\underset{1 \leq i \leq n}{\operatorname{Max}}\left(v_{i} / \sum_{i=1}^{n} v_{i}\right)$ is the total risk rank of the assessed project, the construction risk rank of the Wu Lu Kou subway station is I. Thus, the risk is unacceptable based on Table 2. Government authorities and construction parties should implement additional risk control measures to reduce risk to the acceptable or negligible levels, and prepare or revise the risk warning and emergency response plan.

Furthermore, when finishing the risk assessment of this subway station in 2013/12, the risk events and the losses caused by these risk events continued to be investigated. Figure 9 shows the accumulating economic losses and delay time in the construction from 2012 to 2018. In the initial stage of construction, the loss is bigger than that in other stages, indicating that the construction risk mainly occurs during the initial stage. The project lost a total of 14.7 million CNY and was delayed by 36 months. In addition, one worker died, and seventeen workers were injured during the construction. Obviously, these losses are not acceptable for the construction enterprise, and it is appropriate to affirm that the risk level is I, which is associated with the assessment result of the FANPCE method. Therefore, the FANPCE method can be applied to assess the construction risk in subway station construction.

\section{Method application process and limitation}

The application process of the FANPCE model is shown in Figure 10. Risk factors and risk levels of subway station projects often change dynamically throughout the whole construction process; therefore, during the different stages, FANPCE model should be used repeatedly to obtain the accurate risk evaluations. According to the statistical and investigative data, there are mainly three methods of subway station construction methods, namely the open excavation method, covered excavation method, and semicovered and semiopen methods. The statistics of 178 subway stations are from official news and literature. 9 stations are under construction and 42 subway stations have been constructed by engineers from 9 investigating stations. Therefore, the network structure of risk factors shown in Figure 8 is applicable to a subway station which is constructed with the above three methods. If the subway station is built with other methods or as a part of other projects, the risk factors may differ from the risk factors in Figure 8. New risk factors for a particular site should be investigated, and the risk factors in the network structure should be replaced with new risk factors. The remaining steps are similar as described in this section.

\section{Discussion}

In this study, risk factors of subway station construction in China are identified, and a FANPCE model is developed to assess the construction risk. The model can be used for the risk management, so as to reduce the risk loss. In this study of risk factors. The study shows that, complicated underground pipelines, construction experience and safety consciousness have the highest weight among the rank I of risk factors, whereas out of limits, toxic content and geological disasters have the lowest weight among these factors. In other studies, construction safety is often the focus of risk assessment; the components of the support structure of the foundation pit becomes a risk factor in other studies (Chen \& Song, 2012; Lan \& Zhang, 2006; Li,

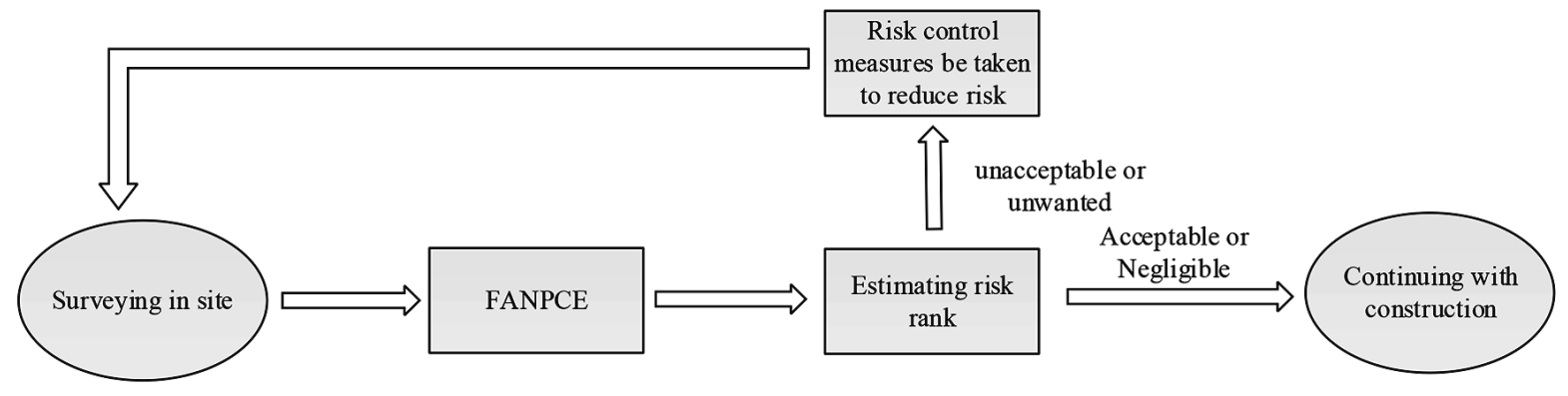

Figure 10. Application of the method 
Du, Zhang, \& Gao, 2009; Ying et al., 2016). Additionally, these risk factors are collected from other studies and lack the field risk investigation. In addition, numerous studies deeply investigate risk assessment methods, while the identification of risk factors is not fully considered (Dikmen \& Birgonul, 2006). Based on the proposed construction project, the results imply that the construction risk rank of the Wu Lu Kou subway station is I. This indicates that there is a high probability of frequent losses caused by risk events. The result implies that, in response to the rank I risk, government authorities and construction parties should implement risk control measures to reduce the risk to acceptable or negligible levels and prepare or revise the risk warning and the emergency response plan. Therefore, a project manager should plan and implement resources for the project. For example, the results indicate that the weight of the safety consciousness of personnel is high. Therefore, some safety training or other measures should be implemented to enhance the safety consciousness of personnel. For example, when there is a high weight of the safety consciousness of personnel, safety training or other measures should be implemented to enhance the safety consciousness of personnel.

However, many mathematical calculations are employed in the model, so relevant mathematics knowledge is required for engineers. In future studies, mathematical calculations can be performed via computer programming. It should be noted that the network structure of risk factors is applicable to a subway station that is constructed by the open excavation method, covered excavation method and semicovered and semiopen methods in China. Risk factors and the identified weights in this study can be employed in the future research. The risk assessment for a subway station can be performed with this method. If the subway station is built by other methods, or at another stage of the project, or different construction risk is assessed in other studies, the risk factors and their weights may differ from those in this research. New risk factors for a particular site should be investigated, and the risk factors in the network structure should be replaced with the new risk factors.

\section{Conclusions}

In the construction of subway stations, effective risk identification and assessment should be performed to reduce the risk and ensure the safety of the construction site. In this study, twelve key risk factors of subway station construction were identified through literature review and questionnaires. The interdependencies among risk factors were represented through the network structure of ANP. The investigation results indicate that the complicated underground pipeline, limited construction experience and poor safety consciousness are weighted as highest risk factors for the studied subway station construction. Then, the weights matrix of single risk factors and interdependencies weights matrix were quantified by integrating the TFN into the ANP. Finally, the total risk rank of the studied project can be quantified through the synthesis of weight matrices with the synthetic operator of FCE. FANPCE method can be as an integration of the network analysis method, fuzzy set theory and FCE method to tackle uncertain and ambiguous risk assessment. In addition, a particular subway station was employed as a case study. The assessment results and the accident loss analysis verify the accuracy and applicability of the FANPCE model to a certain degree.

The advantages of FANPCE are concluded as: (1) the proposed method can be used as an operational tool. Engineers of subway station can consider the interactions of each factor and identify, assess and quantify risks of subway station construction through the proposed method; (2) risk factors can be identified with high risk weights; (3) The model can be applied to quantize and evaluate the risk level throughout the construction process, so as to control of construction risk.

The limitations and disadvantages of the method are concluded as: (1) 12 third-level risk factors of subway station construction may not be completely the same due to different construction environments and methods. Therefore, based on field risk identification, 12 third-level risk factors should be replaced with more exact risk factors and the number of risk factors should be changed; (2) as the number of projects increases, the size of the matrices increases, resulting in a higher number of calculations.

\section{Acknowledgement}

We would like to express our gratitude to all those who have helped us during the writing of this paper. We gratefully acknowledge the help from Associate Professor Dan $\mathrm{Ma}$ at CSU and Dr Guangming Wu at CUMT. We would like to thank ShiningStar Translation (email: shiningstartrans@foxmail.com) for providing linguistic assistance during the preparation of this manuscript.

\section{Author contributions}

Luyuan Wu conceived the study and were responsible for the design and development of the data analysis. Haibo Bai and Yuan Chao were responsible for data collection and analysis. Changyu Xu wrote the first draft of the article.

\section{Funding}

This work was supported by the $<$ Future Scientists Program of "Double First Rate" of China University of Mining and Technology> under Grant [2019WLKXJ076].

\section{Disclosure statement}

We do not have any competing financial, professional, or personal interests from other parties. 


\section{References}

Ahmadi, M., Behzadian, K., Ardeshir, A., \& Kapelan, Z. (2016). Comprehensive risk management using fuzzy FMEA and MCDA technique in highway construction projects. Journal of Civil Engineering and Management, 23(2), 300-310. https://doi.org/10.3846/13923730.2015.1068847

Akyar, E., Akyar, H., \& Duzce, S. A. (2012). A new method for ranking Triangular fuzzy numbers. International Journal of Uncertainty Fuzziness and Knowledge-Based Systems, 20(5), 729-740. https://doi.org/10.1142/S021848851250033X

Antuchevičienè, J., Zavadskas, E. K., \& Zakarevičius, K. (2010). Multiple criteria construction management decisions considering relations between criteria. Technological and Economic Development of Economy, 16(1), 109-125. https://doi.org/10.3846/tede.2010.07

Bayazit, O. (2006). Use of analytic network process in vendor selection decisions. Benchmarking: An International Journal, 13(5), 566-579. https://doi.org/10.1108/14635770610690410

Bjegović, D., Krstić, V., \& Mikulić, D. (2006). Design for durability including initiation and propagation period based on the fuzzy set theory. Werkstoffe Und Korrosion [Materials and Corrosion], 57(8), 642-647. https://doi.org/10.1002/maco.200603996

Bu-Qammaz, A. S., Dikmen, I., \& Birgonul, M. T. (2009). Risk assessment of international construction projects using the analytic network process. Canadian Journal of Civil Engineering, 36(7), 1170-1181. https://doi.org/10.1139/L09-061

Chatterjee, K., \& Kar, S. (2018). Supplier selection in Telecom supply chain management: a Fuzzy-Rasch based COPRAS$\mathrm{G}$ method. Technological and Economic Development of Economy, 24(2), 765-791. https://doi.org/10.3846/20294913.2017.1295289

Chatterjee, K., Bandyopadhyay, A., Ghosh, A., \& Kar, S. (2015). Assessment of environmental factors causing wetland degradation, using Fuzzy Analytic Network Process: A case study on Keoladeo National Park, India. Ecological Modelling, 3(16), 1-13. https://doi.org/10.1016/j.ecolmodel. 2015.07.029

Chatterjee, K., Zavadskas, E. K., Tamošaitienė, J., Adhikary, K., \& Kar, S. (2018). A hybrid MCDM technique for risk management in construction projects. Symmetry, 10(2), 46. https://doi.org/10.3390/sym10020046

Chen, T. T., \& Song, Y. F. (2012). Construction planning decision of subway stations based on AHP- TOPSIS method. Journal of Engineering Management, 4, 33-36.

Chu, H. D., Xu, G. L., Yasufuku, N., Yu, Z., Liu, P. \& Wang, J. F. (2017). Risk assessment of water inrush in karst tunnels based on two-class fuzzy comprehensive evaluation method. Arabian Journal of Geosciences, 10(7), 179. https://doi.org/10.1007/s12517-017-2957-5

Dağdeviren, M., Yüksel, I., \& Kurt, M. (2008). A fuzzy analytic network process (ANP) model to identify faulty behavior risk (FBR) in work system. Safety Science, 46(5), 771-783. https://doi.org/10.1016/j.ssci.2007.02.002

Dai, L. L., \& Li, J. (2016). Study on the quality of private university education based on analytic hierarchy process and fuzzy comprehensive evaluation method. Journal of Intelligent and Fuzzy Systems, 31(4), 2241-2247. https://doi.org/10.3233/JIFS-169064

Debnath, A., Roy, J., Kar, S., Zavadskas, E. K., \& Antucheviciene, J. (2017). A hybrid MCDM approach for strategic project portfolio selection of agro by-products. Sustainability, 9(8), 1302. https://doi.org/10.3390/su9081302
Dikmen, I., \& Birgonul, M. T. (2006). An analytic hierarchy process based model for risk and opportunity assessment of international construction projects. Canadian Journal of Civil Engineering, 33(1), 58-68. https://doi.org/10.1139/105-087

Eskesen, S. D., Tengborg, P., Kampmann, J., \& Veicherts, T. H. (2004). Guidelines for tunnelling risk management: International Tunnelling Association, Working Group no. 2. Tunnelling and Underground Space Technology, 19(3), 217-237. https://doi.org/10.1016/j.tust.2004.01.001

Feng, F., Li, X. B., \& Rostami, J. (2019) Modeling hard rock failure induced by structural planes around deep circular tunnels. Engineering Fracture Mechanics, 205, 152-174. https://doi.org/10.1016/j.engfracmech.2018.10.010

Feng, J.-W. (2006). Fuzzy Delphi Analytic Hierarchy Process and its applications. Mathematics in Practice and Theory, 36(9), 44-48.

Guo, Z., Shang, X. L., \& Li, H. (2011). AHP-based safety assessment model for rail transit system. China Railway Science, 32(3), 123-125.

Hu, Q. F., \& Qin, J. B. (2013). Statistical analysis on accidents of subway tunnel construction from 2003 to 2011 in China. Chinese Journal of Underground Space and Engineering, 9(3), 705-710.

Jie, Y. X., Hu, T., Li, Q. Y., \& Li, G. X. (2004). Application of analytical hierarchy process in the comprehensive safety assessment system of Yangtze River levee. Journal of Tsinghua University (Science and Technology), 44(12), 634-1637.

Klein, J. H., Powell, P. L., \& Chapman, C. B. (1994). Project risk analysis based on prototype activities. Journal of the Operational Research Society, 45(7), 749-757. https://doi.org/10.1057/jors.1994.119

Kuo, Y. C., \& Lu, S. T. (2013). Using fuzzy multiple criteria decision making approach to enhance risk assessment for metropolitan construction projects. International Journal of Project Management, 31(4), 602-614. https://doi.org/10.1016/j.ijproman.2012.10.003

Lan, S. Q., \& Zhang, Q. H. (2006). Risk assessment of deep excavation during construction based on fuzzy theory. Chinese Journal of Geotechnical Engineering, 31(4), 1916-1920.

Li, F. W., Du, X. L, Zhang, M. J., \& Gao, Y. H. (2009). Application of improved AHP in risk identification during open-cut construction of a subway station. Journal of Beijing University of Technology, 38(2), 167-172.

Li, F. W., Du, X. L., \& Zhang, M. J. (2014). Statistical analysis of accidents in metro construction. Chinese Journal of Underground Space and Engineering, 10(2), 474-479.

Li, H. R., Li, Q. M., \& Lu, Y. (2017). Statistical analysis on regularity of subway construction accidents from 2002 to 2016 in China. Urban Rapid Rail Transit, 30(1), 12-19.

Li, X. B., Feng, F., Li, D. Y., Du, K., Ranjith, P. G., \& Rostami, J. (2018). Failure characteristics of granite influenced by sample height-to-width ratios and intermediate principal stress under true-triaxial unloading conditions. Rock Mechanics and Rock Engineering, 51(5), 1321-1345. https://doi.org/10.1007/s00603-018-1414-4

Lin, C. K., Chen, Y. S., \& Chuang, H. M. (2016). Improving project risk management by a hybrid MCDM model combining DEMATEL with DANP and VIKOR methods - An example of cloud CRM. In J. Hung, N. Yen, \& K. C. Li. (Eds.), Frontier Computing (vol. 375, pp. 1033-1040). Springer, Singapore. https://doi.org/10.1007/978-981-10-0539-8_101

Ma, D., Cai, X., Li, Q., \& Duan, H. (2018b). In-situ and numerical investigation of groundwater inrush hazard from grouted 
karst collapse pillar in longwall mining. Water, 10(9), 1187. https://doi.org/10.3390/w10091187

Ma, D., Cai, X., Zhou, Z., \& Li, X. (2018a). Experimental investigation on hydraulic properties of granular sandstone and mudstone mixtures. Geofluids, 9216578. https://doi.org/10.1155/2018/9216578

Ma, D., Duan, H., Liu, J., Li, X., \& Zhou, Z. (2019). The role of gangue on the mitigation of mining-induced hazards and environmental pollution: An experimental investigation. Science of the Total Environment, 664, 636-448. https://doi.org/10.1016/j.scitotenv.2019.02.059

Ma, D., Rezania, M., Yu, H. S., \& Bai, H. B. (2017). Variations of hydraulic properties of granular sandstones during water inrush: Effect of small particle migration. Engineering Geology, 217, 61-70. https://doi.org/10.1016/j.enggeo.2016.12.006

Mahamid, I. (2011). Risk matrix for factors affecting time delay in road construction projects: owner's perspective. Engineering, Construction and Architectural Management, 18(6), 609617. https://doi.org/10.1108/09699981111180917

Meade, L., \& Sarkis, J. (2002). A conceptual model for selecting and evaluating third-party reverse logistics providers. Supply Chain Management, 7(5), 283-295. https://doi.org/10.1108/13598540210447728

Nývlt, O., Prívara, S., \& Ferkl, L. (2011). Probabilistic risk assessment of highway tunnels. Tunnelling and Underground Space Technology, 26(6), 71-82. https://doi.org/10.1016/j.tust.2010.06.010

Qian, Q. H. (2012). Challenges faced by underground projects construction safety and counter- measures. Chinese Journal of Rock Mechanics and Engineering, 31(10), 1945-1956.

Roy, J. (2010). Dealing with uncertainty: selecting a risk analysis tool on the basic project characteristics and phases (Master thesis). Department of Civil, Environmental and Architectural Engineering, University of Colorado, USA.

Roy, J., Chatterjee, K., Bandyopadhyay, A., \& Kar, S. (2018). Evaluation and selection of medical tourism sites: A rough analytic hierarchy process based multi-attributive border approximation area comparison approach. Expert Systems, 35(1), ID 12232. https://doi.org/10.1111/exsy.12232

Saaty, T. L. (1999). Fundamentals of the analytic network process. In Proceedings of the Fifth International Symposium on the Analytic Hierarchy Process. Kobe, Japan.

Saaty, T. L. (2001). Decision making with dependence and feedback: The Analytic network process. Ellsworth Avenue: Pittsburgh Publications.

Saaty, T. L. (2004). Fundamentals of the analytic network process-dependence and feedback in decision-making with a single network. Journal of Systems Science and Systems Engineering, 13(2), 129-157. https://doi.org/10.1007/s11518-006-0158-y

Santos, R., \& Jungles, A. (2016). Risk level assessment in construction projects using the schedule performance index. Journal of Construction Engineering, ID 5238416, 1-8. https://doi.org/10.1155/2016/5238416

Seyedhoseini, S. M., Noori, S., \& Hatefi, M. A. (2009). An integrated methodology for assessment and selection of the project risk response actions. Risk Analysis, 29(5), 752-763. https://doi.org/10.1111/j.1539-6924.2008.01187.x

Sharma, H. K., Roy, J., Kar, S., \& Prentkovskis, O. (2018). Multi criteria evaluation framework for prioritizing Indian railway stations using modified rough AHP-Mabac method. Transport and Telecommunication, 19(2), 113-127. https://doi.org/10.2478/ttj-2018-0010
Shin, D., Shin, Y., \& Kim, G. (2016). Comparison of risk assessment for a nuclear power plant construction project based on analytic hierarchy process and fuzzy analytic hierarchy process. Journal of Building Construction \& Planning Research, 4(3), 157-171. https://doi.org/10.4236 /jbcpr.2016.43010

Son, N. T. K. (2018). A foundation on semigroups of operators defined on the set of triangular fuzzy numbers and its application to fuzzy fractional evolution equations. Fuzzy Sets and Systems, 347, 1-28. https://doi.org/10.1016/j.fss.2018.02.003

Tang, Y. C., \& Beynon, M. J. (2005). Application and development of a fuzzy analytic hierarchy process within a capital investment study. Journal of Economics \& Management, 1(2), 207-230.

Tavana, M., Zandi, F., \& Katehakis, M. N. (2013). A hybrid fuzzy group ANP-TOPSIS framework for assessment of e-government readiness from a CIRM perspective. Information and Management, 50(7), 383-397. https://doi.org/10.1016/j.im.2013.05.008

Taylan, O., Bafail, A. O., Abdulaal, R. M., \& Kabli, M. R. (2014). Construction projects selection and risk assessment by fuzzy AHP and fuzzy TOPSIS methodologies. Applied Soft Computing, 17(4), 105-116. https://doi.org/10.1016/j.asoc.2014.01.003

Ulubeyli, S., \& Kazaz, A. (2016). Fuzzy multi-criteria decision making model for subcontractor selection in international construction projects. Technological and Economic Development of Economy, 22(2), 210-234. https://doi.org/10.3846/20294913.2014.984363

Vafadarnikjoo, A., Mobin, M., \& Firouzabadi, S. (2016). An intuitionistic fuzzy-based DEMATEL to rank risks of construction projects. In Proceedings of the International Conference on Industrial Engineering and Operations Management (pp. 1366-1377). Detroit, Michigan, USA.

Valipour, A., Yahaya, N., Noor, N. Md, Antucheviciene, J., \& Tamošaitiene, J. (2017). Hybrid SWARA-COPRAS method for risk assessment in deep foundation excavation project-An Iranian case study. Journal of Civil Engineering and Management, 23(4), 524-532. https://doi.org/10.3846/13923730.2017.1281842

Wang, L. K., \& Hak-Keung, L. (2018). A new approach to stability and stabilization analysis for continuous-time TakagiSugeno fuzzy systems with time delay. IEEE Transactions on Fuzzy Systems, 26(4), 2460-2465. https://doi.org/10.1109/TFUZZ.2017.2752723

Xiong, Z. M., Lu, H., Wang, M. Y., Qian, Q. H., \& Rong, X. L. (2018). Research progress of safety risk management for large scale geotechnical engineering construction in China. Rock and Soil Mechanics, 39(10), 1-14.

Yang, Y. Q., Said, M. E, Lin, Z. B., \& Zheng, X. Y. (2018). Evaluating highway traffic safety: An integrated approach. Journal of Advanced Transportation, ID 4598985. https://doi.org/10.11 55/2018/4598985

Ying, G. Z., Wang, P. C., Zhu, D. Y., Lei, X. S., \& Qin, Z. (2016). Risk assessment of subway construction based on fuzzy comprehensive evaluation model. Chinese Journal of Underground Space and Engineering, 12(4), 539-545.

Zadeh, L. A. (1965). Fuzzy sets. Information \& Control, 8(3), 338-353. https://doi.org/10.1016/S0019-9958(65)90241-X

Zavadskas, E. K., Turskis, Z., \& Tamošaitiene, J. (2010). Risk assessment of construction projects. Journal of Civil Engineering and Management, 16(1), 33-46. https://doi.org/10.3846/jcem.2010.03 
Zhang, X. P., Wang, J., \& Hu, M. L. (2011). Application of FTA in safety assessment of row piles of excavation engineering. Chinese Journal of Geotechnical Engineering, 33(6), 960-965. https://doi.org/10.1063/1.4704260

Zhao, X. J., Chen, L., Pan, W., \& Lu, Q. C. (2017). AHP-ANPFuzzy integral integrated network for evaluating performance of innovative business models for sustainable building. Journal of Construction, Engineering and Management, 143(8), ID 04017054. https://doi.org/10.1061/(ASCE)CO.1943-7862.0001348

Zimmerman, H. J. (2001). Fuzzy set theory and its applications. London: Kluwer Academic Publishers. https://doi.org/10.1007/978-94-010-0646-0

\section{Notations}

\section{Variables and functions}

$l \quad-$ lower bound of the fuzzy number;

$m \quad$ - intermediate value of a fuzzy number;

$u \quad$ - upper bound of the fuzzy number;

$v_{1}, v_{2}, v_{3}, v_{4}$ - final weight of risk level I, II, III, IV;

$R_{(i j) \mathrm{V}_{\mathrm{I}}}, R_{(i j) \mathrm{V}_{\mathrm{II}}}, R_{(i j) \mathrm{V}_{\mathrm{III}}}, R_{(i j) \mathrm{V}_{\mathrm{IV}}}$ - weights of each TLRF at risk level I, II, III, IV when taking the probability of generating risk, the loss degree and the controllability of the risk as criteria;

$a_{i j} \quad-$ weight of subblock $i$ in super matrix $\mathbf{W}$;

$\mu_{F}(x)$ - Degree of Membership Function.

\section{Abbreviations}

FTA - fault tree analysis;

FMCDM - Fuzzy multiple criteria decision making;

AHP - Analytic Hierarchy Process;

ANP - Analytic Network Process;

FCE - Fuzzy Comprehensive Evaluation;

FANPCE - Fuzzy Analytic Network Process Comprehensive Evaluation;

TLRF - Third Level Risk Factors;

FCM - Fuzzy Comparison Matrix;

FWM - Fuzzy Weight Matrix. 